\title{
Processing of Mutant $\beta$-Amyloid Precursor Protein and the Clinicopathological Features of Familial Alzheimer's Disease
}

\author{
Christopher Bi ${ }^{1}$, Stephanie $\mathrm{Bi}^{1}$, Bin $\mathrm{Li}^{1,2^{*}}$ \\ ${ }^{1}$ Washington Institute for Health Sciences, Arlington, VA 22203, USA \\ ${ }^{2}$ Department of Biochemistry and Molecular \& Cellular Biology, Georgetown University Medical Center, \\ Washington DC 20057, USA
}

[Received March 18, 2018; Revised April 23, 2018; Accepted April 25, 2018]

\begin{abstract}
Alzheimer's disease (AD) is a complex, multifactorial disease involving many pathological mechanisms. Nonetheless, single pathogenic mutations in amyloid precursor protein (APP) or presenilin 1 or 2 can cause AD with almost all of the clinical and neuropathological features, and therefore, we believe an important mechanism of pathogenesis in AD could be revealed from examining pathogenic APP missense mutations. A comprehensive review of the literature, including clinical, neuropathological, cellular and animal model data, was conducted through PubMed and the databases of Alzforum mutations, HGMD, UniProt, and AD\&FTDMDB. Pearson correlation analysis combining the clinical and neuropathological data and aspects of mutant APP processing in cellular models was performed. We find that an increase in Aß42 has a significant positive correlation with the appearance of neurofibrillary tangles (NFTs) and tends to cause an earlier age of AD onset, while an increase in A $\mathbf{\beta 4 0}$ significantly increases the age at death. The increase in the $\alpha$-carboxyl terminal fragment (CTF) has a significantly negative correlation with the age of AD onset, and $\beta$-CTF has a similar effect without statistical significance. Animal models show that intracellular A $\beta$ is critical for memory defects. Based on these results and the fact that amyloid plaque burden correlates much less well with cognitive impairment than do NFT counts, we propose a "snowball hypothesis": the accumulation of intraneuronal NFTs caused by extracellular A $\mathrm{A42}$ and the increase in intraneuronal APP proteolytic products (CTFs and A $\mathrm{As}$ ) could cause cellular organelle stress that leads to neurodegeneration in $\mathrm{AD}$, which then resembles the formation of abnormal protein "snowballs" both inside and outside of neurons.
\end{abstract}

Key words: Alzheimer's disease, APP mutation, APP processing, clinico-pathological features, cellular models, animal models

With an estimated 5.5 million cases to date, Alzheimer's disease $(\mathrm{AD})$ is one of the most prevalent neurological dementia disorders in the United States, and the number of cases is projected to rise to over 13 million by 2050 [1]. According to the World Alzheimer Report 2016, there were 46.8 million people living with dementia in 2015 , and the number of cases worldwide is projected to reach 131.5 million by 2050 [2]. AD is characterized by the gradual loss of cognitive and behavioral functions, which accounts for $50-70 \%$ of dementia cases. Post-mortem examinations of $\mathrm{AD}$ patients reveal amyloid plaques composed of $\beta$-amyloid $(A \beta)$ peptides and neurofibrillary

*Correspondence should be addressed to: Dr. Bin Li, Department of Biochemistry and Molecular \& Cellular Biology, Georgetown University Medical Center, 3900 Reservoir Road, Washington DC 20057, United States. Email: bl444@ georgetown.edu

Copyright: ( $) 2018 \mathrm{Bi} \mathrm{C}$ et al. This is an open-access article distributed under the terms of the Creative Commons Attribution License, which permits unrestricted use, distribution, and reproduction in any medium, provided the original author and source are credited. 
tangles (NFTs) composed of hyperphosphorylated tau protein, which are thought to be linked to the death of neurons [3]. Approximately $75 \%$ of cases are termed sporadic $\mathrm{AD}$ with no apparent connection to family history, while the other $25 \%$ are related to family history. Among all AD cases, approximately $95 \%$ are late onset (age $>60$ or 65 years), and $5 \%$ are early onset (age $<65$ years). Fewer than $2 \%$ of $\mathrm{AD}$ cases belong to early-onset familial $\mathrm{AD}$ (EOFAD). $10 \%$ to $15 \%$ of EOFAD are caused by amyloid precursor protein (APP) mutation, and $20 \%$ to $70 \%$ of EOFAD are caused by presenilin 1 (PS1) mutation; in rare cases, EOFAD can be caused by presenilin 2 (PS2) mutations [4]. Currently, there is no cure for $\mathrm{AD}$ - only a few drugs, such as acetylcholinesterase inhibitors and memantine that can temporarily alleviate cognitive and behavioral symptoms [5]. To find an effective treatment strategy, many hypotheses have been proposed to explain the pathogenesis of $\mathrm{AD}$, including the amyloid cascade hypothesis [6], the presenilin hypothesis [7], the APP matrix hypothesis [8], hyperphosphorylation of tau protein [9], neuroinflammation [10], oxidative stress [11], mitochondrial dysfunction [12], endoplasmic reticulum (ER) stress [13], dysregulation of glucose [14], cholesterol and metal metabolism [15], and aberrant cell cycle reentry [16]. As a complex, multifactorial disease, it is reasonable to believe that $\mathrm{AD}$ involves a variety of pathological mechanisms. However, familial $\mathrm{AD}$ and sporadic $\mathrm{AD}$ are largely indistinguishable with respect to symptoms - namely, single pathogenic missense mutations in APP, PS1 or PS2 can cause AD with almost all of the clinical and neuropathological features. Familial AD that is caused by missense mutations of APP can provide a disease model to reveal an important mechanism of pathogenesis in $\mathrm{AD}$.

In this paper, we first briefly describe the function and processing of normal APP as well as the neuropathological features of $\mathrm{AD}$. We then review the clinical and neuropathological characteristics of $A D$ caused by APP missense mutations, mutant APP processing in cellular models, and the histological and behavioral manifestations of transgenic ( $\mathrm{Tg}$ ) animal models. A total of 27 APP missense mutations are included in this review. Next, we analyzed the correlation between clinical and neuropathological data as well as the features of mutant APP processing in cellular models. Finally, based on the analysis results, we propose the "Snowball Hypothesis": accumulation of extracellular A $\beta 42$ does not directly cause neuronal death; instead, their gradual accumulation causes NFTs formation and organelle stress within neurons. Intracellular APP proteolytic products also aggravate organelle stress. This abnormal intracellular protein accumulation can cause neurons to slowly lose function and finally die.

\section{The function and processing of normal APP}

The APP gene, which is located on chromosome 21 in humans, encodes a type I transmembrane protein that exists in 8 different isoforms, with the three main isoforms being APP695, APP751, and APP770, containing 695, 751 , and 770 amino acids, respectively [17]. APP751 and APP770 both contain a 56-amino acid-long Kunitz Protease Inhibitor (KPI) region and are primarily expressed by microglia and meninges cells in the brain, while APP695, the dominant isoform, is primarily expressed by neurons. In fact, it is estimated that KPIcontaining isoforms of APP account for less than 14\% of the APP produced in the brain, but interestingly, the mRNAs of these isoforms have been observed at elevated levels in $A D$ patients and are thought to be related to $A \beta$ deposition [18].

APP belongs to a group of proteins that includes APPlike protein 1 (APLP1) and APP-like protein 2 (APLP2). They all are type I transmembrane proteins and are processed in a similar fashion, but the $A \beta$ domain is unique to the APP gene. Studies suggest that there are certain redundancies between these proteins. For example, studies demonstrate that mice lacking a single APP family member are viable and fertile, showing certain abnormal physiological changes such as decreased brain size and weight. However, APP/APLP2 and APLP1/APLP2 double-null mice and APP/APLP1/APLP2 triple-null mice show mortality in early development, while APP/APLP1 double-null mice are viable, suggesting that APLP2 is the most important $[19,20]$.

The APP family is thought to be involved in intercellular adhesion based on the study of certain conserved regions. For example, the extracellular portion of APP has been found to associate with heparin, collagen type I, and laminin. In addition, the E2 domain was found to form antiparallel dimers, and transcellular APP/APP interactions induce presynaptic specializations in cocultured cells, signifying APP proteins as a class of synaptic adhesion molecules. Through its adhesion properties, APP is also known to possess neural and synaptotropic functions, stimulating short-term neuronal adhesion and long-term neurite growth [21]. The notion that soluble APPs $\alpha$, a derivative of APP, is essential to neuronal protective functions is supported by its correlation to higher synaptic density and its role in spatial memory [22]. Other functions of APP and its fragments, such as axon pruning and degeneration [23], intracellular signaling, and apoptosis, are still ambiguous [21].

In non-polarized cells, APP is first synthesized in the ER and is then transported to the Golgi apparatus and trans-Golgi network (TGN), in which it is found in the highest steady-state concentration. A portion of the APP 
(estimated to be approximately $\sim 10 \%$ ) is destined for the plasma membrane, and it is posttranslationally modified by $\mathrm{N}$-linked and $\mathrm{O}$-linked glycosylation, palmitoylation, and tyrosine sulfation, among others. APP that reaches the plasma membrane without cleavage within minutes is rapidly internalized in endosomes. A fraction of these endosomes is recycling endosomes that release it back to the plasma membrane, while others undergo lysosomal degradation. $\alpha$-Secretases such as ADAM9, ADAM10, and ADAM17, belonging to the "disintegrin and metalloprotease" family, are thought to reside primarily at the cell membrane, cleaving APP to form the APPs $\alpha$ derivative and a carboxyl terminal fragment $(\alpha-\mathrm{CTF}$ or C83) in the non-amyloidogenic pathway. $\alpha$-CTFs are further cleaved by $\gamma$-secretase to form a truncated $A \beta$ peptide called $\mathrm{p} 3$ and the APP intracellular domain (AICD). $\beta$-Secretases, one of which is known as $\beta$ secretase 1 (BACE1), are thought to be localized in the acidic environments of the TGN, Golgi, and endosomes and cut APP at the $\beta$ sites in the amyloidogenic pathway, producing the ectodomain APPs $\beta$. The carboxyl terminal fragment of APP that are leftover, known as $\beta$-CTF (C99), remains plasma membrane-bound and is further cleaved by $\gamma$-secretase to form A $\beta$ and AICD. APP processing in neurons is thought to be similar in non-polarized cells, but one difference is that after leaving the neuronal TGN, APP is transported to axons and dendrites [19, 24].

\section{Neuropathological features of Alzheimer's disease}

$\mathrm{AD}$ is typically diagnosed in a post-mortem examination of the brain. Macroscopic features of an AD brain include cortical atrophy that mainly affects the medial temporal lobes. Due to cortical atrophy, certain phenotypes, such as lateral ventricular and temporal horn dilatation, can manifest themselves. Microscopic features include neurofibrillary tangles (NFTs), amyloid plaques, cerebral amyloid angiopathy (CAA), glial responses, neuron and synapse loss, granuovacuolar degeneration, Hirano bodies and Lewy bodies [25].

NFTs are primarily composed of paired helical filaments, which are constructed from aberrant hyperphosphorylated tau protein [26]. NFTs are classified into three main categories: 1) pre-NFTs appearing in the cytoplasm of otherwise-normal neurons; 2) mature intraneuronal NFTs consisting of cytoplasmic filaments that displace the nucleus towards the periphery of the soma in neurons; and 3) "ghost" NFTs, which are characterized by neuronal death and cytoplasmic staining of tau. NFT stage advancement parallels neuron and synapse loss. The correlation between the progression of NFTs and the development of dementia symptoms has been firmly established [27].
Amyloid plaques are mainly composed of the extracellular accumulation of $A \beta 40$ and $A \beta 42$ derived from APP after cleavage by $\beta$ - and $\gamma$-secretases. A $\beta 42$ is considered to be more insoluble and has a higher chance of polymerization and therefore is typically more abundant in plaques, while $A \beta 40$ is investigated as the primary constituent in CAA. Amyloid plaques can be categorized into diffuse and dense-core plaques. A drastic difference between amyloid plaques and NFTs is that amyloid plaques occur mainly in the isocortex. Braak and Braak distinguished between three stages of amyloid plaques: Stage 1, occurring mainly in the isocortex; Stage 2 , in the limbic region; and Stage 3, in the subcortical layer [28]. Despite this, clinicopathological studies showed that the amyloid burden does not correlate with the severity or the duration of dementia [27].

Although Alzheimer's disease is characterized by NFTs and amyloid plaques, some $38.2 \%$ of non-demented people may qualify in the "intermediate" or "high likelihood of AD" categories of the National Institute on Aging (NIA) - Reagan criteria indicated by the presence of moderate neuritic plaques and NFTs in limbic regions [29]. In fact, certain asymptomatic AD individuals seem resistant to NFTs and amyloid burden, perhaps contradicting the correlation between NFTs/amyloid and neuronal death. Bussièreet $e t$ al. found that a considerable number of neurons containing mature intraneuronal NFTs can survive for almost two decades [30]. Other evidence also suggests that the presence of NFTs does not directly cause neuronal dysfunction [31]. Therefore, we might not say that the accumulation of $A \beta$ and NFTs are "toxic" rather, they are an increasing burden to neurons.

CAA, identified by deposits of $A \beta$ in leptomeningeal arteries, small and medium-sized arterioles, and cortical capillaries of the central nervous system, is found in $\sim 80 \%$ of $\mathrm{AD}$ patients. Leptomeningeal arteries are typically affected more than cortical arteries, and CAA can lead to complications such as lobar hemorrhages [25].

Activated microglia and astrocytes are commonly correlated negatively with dense-core plaques, but Serrano-Pozo et al. found that glial responses also correlated positively with NFT burden. This finding argued against the stereotypical relationship between glial cells and amyloid plaques and suggested that reactive glia might contribute to the ongoing neurodegeneration [32].

Cortical atrophy is mainly caused by neuronal loss. NFTs levels parallel neuronal loss in regional and laminar patterns, but in certain regions, neuronal loss has been found to be greater, suggesting neuronal loss as a better measure of cognitive damage [33]. Synaptic loss has also matched neuronal loss in the same spatiotemporal and laminar patterns, but synaptic loss can exceed the existing neuronal loss, which suggests that loss of neuronal function precedes neuronal death [34]. 
Hirano bodies and vascular degeneration may also appear as lesions in the hippocampal formation. Studies have suggested that these bodies are associated with ER stress $[35,36]$. Lewy bodies are abnormal aggregates of $\alpha$-synuclein that develop inside neurons in Parkinson's disease (PD), commonly associated with Lewy body dementia. Approximately $70 \%$ of patients with sporadic $\mathrm{AD}$ and some familial $\mathrm{AD}$ display Lewy body-like pathology in the amygdala and limbic structures [37, 38].

\section{Familial AD caused by missense mutations in APP}

A comprehensive literature search of the PubMed, Alzforum, HGMD, UniProt, and AD\&FTDMDB databases was conducted; 69 missense mutations were reported in the above databases. Among them, 36 mutations (A201V, A235V, D243N, E246K, T276S, V287G，E296K，P299L，R328W，V340M， R468H, A479S, K496Q, A500T, K510N, Y538H, V562I, E599K, T600M, S614G, P620A, P620L, N660Y, T663M, E665D, H677R, G708G, G709S, V710G, A713V, I718L, T719N, L720S, M722K, H733P, and A741S) are not pathogenic or are unclear; 7 mutations (E693N, L705V, A713T, T714A, I716M, T719P, and L723R) are pathogenic, but their effects on APP processing have not been studied in cellular models; 25 APP pathogenic missense mutations (KM670/671NL, A673V, D678H, D678N, E682K, K687N, A692G, E693del, E693G, E693K, E693Q, D694N, T714I, V715A, V715M, I716F, I716T, I716T, V717F, V717G, V717I, V717L, L723P, K724N, K724M) and 1 protective mutation (A673T) are included in this review. All of these mutations are clustered around $\alpha-, \beta-$ and particular $\gamma$-secretase cleavage sites that influence APP proteolysis. APP pathogenic missense mutations cause familial AD with dominant inheritance, except for the A673V mutation, which shows a recessive Mendelian pattern of inheritance [39]. The mean ages of onset and death were calculated based on available references, and the pathological findings from different references are summarized. We give priority to neuronal cell models when making a judgment on the effects of APP mutations in different cell lines. Tg animal model studies with a single pathogenic APP mutation are also discussed in this review.

\section{KM670/671NL (Swedish) mutation}

The mean age of onset was 53.8 years $(n=70)$, and the mean age of death was 62.3 years $(n=42)$. Brain imaging examinations include computed tomography (CT), magnetic resonance imaging (MRI) and single photon emission computed tomography (SPECT), showing cortical atrophy and cerebral blood flow reduction. The reported neuropathological characteristics included
NFTs, amyloid plaques, CAA, and Lewy bodies [40 - 47]. Studies of APP processing in cellular models showed that intracellular $A \beta$ increased compared to the WT control; $\alpha$ CTF levels remained constant; $\beta$-CTF increased; total secreted $A \beta, A \beta 40$ and 42 increased; and the ratio of A $\beta 42 / A \beta 40$ did not change [48-53]. The APP23 mouse model carrying the M670/671NL mutation (APP 751) driven by the murine Thy1 promoter had 7-fold higher expression of mutant human APP compared to endogenous mouse APP. Histological studies showed no NFTs, while amyloid plaques appeared in the cortex and hippocampus at 6 months, and CAA appeared at 19 months. Activation of microglia appeared at 14 months, and neuronal loss (14-28\%) was found in the CA1 region of the hippocampus in 14- to 18-month-old mice. Memory defects were found at 3 months [54-60]. The TAS10 (thy1-APPswe) mouse model carries the KM670/671NL mutation (APP695) driven by the murine Thy1 promoter. Histological studies showed no NFTs, but phosphorylated tau appeared in the hippocampus and cortex at 24 months, and amyloid plaques appeared in the cortex and hippocampus at 12 months. Furthermore, activation of microglia and astrocytes appeared at 6 months. While no neuronal loss was found, synaptic loss appeared at 24 months, and the number of lysosomes increased in neurons of the dentate gyrus at 6 months. Memory defects were found at 6 months [61]. The Tg-Swe mouse model carries the KM670/671NL mutation (APP695) driven by the murine Thy 1 promoter. Histological studies showed no NFTs, amyloid plaques appeared in the cortex and hippocampus at 12 months, and CAA appeared at 12 months. Intraneuronal $A \beta$ accumulation occurred at 6 months, activation of microglia and astrocytes appeared at 12 months. No neuronal loss was found, and memory defects are not known [62-64]. The APPSwe (line C3-3) mouse model carries a chimeric mouse/human APP695 containing a "humanized" $A \beta$ domain with the KM670/671NL mutation driven by the mouse prion protein promoter. These mice showed 3-fold higher expression of mutant human APP compared to endogenous mouse APP. Histological studies showed that amyloid plaques appeared in the cortex and hippocampus at 18 months, but memory defects were not found $[65,66]$. The APPSwe-NSE mouse model carries human APP695 containing the KM670/671NL mutation driven by the neuron-specific enolase (NSE) promoter. Histological studies showed widespread, intensive staining of $A \beta 42$ in the neurons of the cortex and hippocampus at 12 months but no amyloid plaques. The number of TUNEL-stained nuclei increased. Biochemical studies showed that $A \beta 42$ and tau phosphorylation increased at 12 months. Memory defects were found at 12 months [67]. The Tg2576 mouse model carries human APP695 containing the KM670/671NL mutation driven by the hamster prion 
protein. Histological studies showed that there were no NFTs, while amyloid plaques appeared in the cortex and hippocampus at 11 months. Activation of microglia appeared at 10 months, but no neuronal loss was found. Dendritic spine loss appeared at 4.5 months in the CA1 region of the hippocampus, and memory defects were found at 9 months $[68,69]$.

\section{A673T (Icelandic) mutation}

This mutation has been reported to have protective effects. The age of onset for 1 dementia case was 104 years. The reported neuropathological characteristics included NFTs, no amyloid plaques, and mild CAA. Studies of APP processing in cellular models showed that $\beta-\mathrm{CTF}$ decreased compared with WT control; total secreted $A \beta$, $A \beta 40$ and $A \beta 42$ all decreased; the ratio of $A \beta 42 / A \beta 40$ all did not change; $A \beta 40$ and $A \beta 42$ polymerization decreased [70-74]. There is no Tg animal model available for this mutation.

\section{A673V mutation}

Only one case was reported, the age of onset was 36.0 years, and the age of death was 46 years. Brain imaging examination (MRI) showed cortical atrophy. The reported neuropathological characteristics included NFTs, amyloid plaques, CAA, activation of microglia and astrocytes, and neuronal loss [39, 75]. Studies of APP processing in cellular models showed that $\beta$-CTF increased compared to WT control; total secreted $A \beta, A \beta 38, A \beta 40$ and $A \beta 42$ all increased; the ratio of $A \beta 42 / A \beta 40$ showed no change; and $A \beta 40$ polymerization increased $[39,72,73]$. There is no $\mathrm{Tg}$ animal model available for this mutation.

\section{D678H (Taiwanese) mutation}

Only one case was reported, and the age of onset was 51.0 years. Brain imaging examinations (CT and SPECT) showed cortical atrophy and reduced cerebral blood flow. Neuropathological reports are not available. Studies of APP processing in cellular models showed that intracellular $A \beta$ did not change compared with WT control, whereas $\beta-\mathrm{CTF}$, total secreted $\mathrm{A} \beta, \mathrm{A} \beta 40$ and $\mathrm{A} \beta 42$, and the ratio of $\mathrm{A} \beta 42 / \mathrm{A} \beta 40$ all increased. $A \beta 40$ polymerization increased, but $\mathrm{A} \beta 42$ aggregation decreased, while internalization of APP increased and degradation of APP in lysosomes increased [76, 77]. There is no animal model available for this mutation.

\section{D678N (Tottori) mutation}

The mean age of onset was 58.8 years $(n=3)$, and the mean age of death was 70.3 years $(n=3)$. Brain imaging examinations (MRI and SPECT) showed cortical atrophy and cerebral blood flow reduction. Neuropathological reports are not available. Studies of APP processing in cellular models reported that intracellular $\mathrm{A} \beta$ showed no change compared with WT control; $\beta$-CTF showed no change; and the total secreted $\mathrm{A} \beta, \mathrm{A} \beta 40, \mathrm{~A} \beta 42$, and the ratio of $A \beta 42 / A \beta 40$ all showed no change. $A \beta 42$ polymerization increased [78-80]. There is no animal model available for this mutation.

\section{E682K (Leuven) mutation}

The mean age of onset was 61.0 years $(n=2)$, and the age of death was 83 years $(n=1)$. Brain imaging examination (MRI) showed hippocampal atrophy. Neuropathological reports are not available. Studies of APP processing in cellular models showed that $\alpha-C T F$ did not change compared with WT control; $\beta-\mathrm{CTF}$, total secreted $\mathrm{A} \beta$, $A \beta 40$ and 42 , and the ratio of $A \beta 42 / A \beta 40$ all increased [81]. There is no animal model available for this mutation.

\section{K687N mutation}

The mean age of onset was 56.3 years $(n=3)$, and the mean age of death was 68.3 years $(n=3)$. Brain imaging examination (MRI) showed cortical atrophy. Neuropathological reports are not available. Studies of APP processing in cellular models showed that membrane-associated APP increased compared to WT control; $\alpha$ - and $\beta$-CTF decreased; total secreted $A \beta, A \beta 40$, $\mathrm{A} \beta 42$, and the ratio of $\mathrm{A} \beta 42 / \mathrm{A} \beta 40$ increased; and resistance to proteolytic degradation with neprilysin increased [82]. There is no animal model available for this mutation.

\section{A692G (Flemish) mutation}

The mean age of onset was 46.0 years $(n=15)$, and the mean age of death was 54.6 years $(n=15)$. The reported neuropathological characteristics included cortical atrophy, hemorrhagic infarction, NFTs, amyloid plaques, CAA, activation of microglia and astrocytes, and neuronal loss [46, 83-85]. Studies of APP processing in cellular models showed that $\alpha$-CTF did not change compared to WT control; $\beta$-CTF increased; total secreted $A \beta, A \beta 40,42$ and the ratio of $A \beta 42 / A \beta 40$ all increased; $A \beta 40$ and 42 polymerizations decreased; and the resistance to proteolytic degradation with neprilysin and insulindegrading enzyme increased [81, 86-92]. There is no animal model available for this mutation. 


\section{E693del (Osaka) mutation}

The mean age of onset was 49.7 years $(n=7)$, and the mean age of death was 59.5 years $(n=4)$. Brain imaging examinations (MRI and SPECT) showed cortical atrophy and cerebral blood flow reduction. [18F]Fluorodeoxyglucose positron emission tomography (FDG-PET) showed reduced glucose metabolism (hypometabolism) in the cerebral cortex. PET amyloid imaging showed less $A \beta$ deposition than in typical idiopathic AD brains. Neuropathological reports are not available. Studies of APP processing in cellular models showed that intracellular $A \beta$ increased compared to WT control; total secreted $A \beta, A \beta 40$ and $A \beta 42$ decreased; the ratio of $A \beta 42 / A \beta 40$ did not change; $A \beta 40$ and 42 polymerizations increased; and the resistance to proteolytic degradation with neprilysin and insulindegrading enzyme increased [93-95]. The APP E693 $\Delta-\mathrm{Tg}$ (Osaka) mouse model carrying the Osaka mutation (APP695) driven by the mouse prion promoter expressed similar amounts of mutant human APP and endogenous mouse APP. Histological studies showed no NFTs, but abnormal tau phosphorylation was found at 8 months. There were no amyloid plaques, while intraneuronal $A \beta$ accumulation in the hippocampus and cerebral cortex occurred at 8 months. Activation of microglia appeared at 12 months; activation of astrocytes appeared at 18 months; neuronal loss in the $\mathrm{CA} 3$ region of the hippocampus was found at 18 months; synaptic loss in the CA3 region appeared at 8 months. Memory defects were found at 8 months $[96,97]$. The OSK-KI mouse model carrying the Osaka mutation was generated by knock-in of this mutation into endogenous mouse APP. The levels of APP expression in homozygous and heterozygous mice were similar to those of endogenous APP in non-knock-in mice. Histological studies showed no NFTs, but abnormal tau phosphorylation was found in homozygotes at 8 months. There were no amyloid plaques, while intraneuronal $A \beta$ accumulation in the hippocampus and cerebral cortex occurred in homozygotes at 8 months, and heterozygotes showed only slight $A \beta$ accumulation at 24 months. Activation of microglia and astrocytes appeared at 12 months in homozygotes; gliosis was not found in heterozygotes; neuronal loss in the hippocampus and entorhinal cortex was found at 24 months; synaptic loss appeared at 8 months in homozygotes and at 24 months in heterozygotes. Memory defects in homozygotes were found at 4 months [98].

\section{E693G (Arctic) mutation}

The mean age of onset was 57.0 years $(n=43)$, and the mean age of death was 65.5 years $(n=15)$. Brain imaging examinations (MRI and SPECT) showed cortical atrophy and cerebral blood flow reduction. The reported neuropathological characteristics included NFTs, amyloid plaques, intracellular $\mathrm{A} \beta$ immunoreactivity, CAA, activation of astrocytes, and neuronal loss [44, 99-103]. Studies of APP processing in cellular models showed that total secreted A $\beta 38$ increased compared to the WT control; $A \beta 40$ did not change; $A \beta 42$ and the ratio of $\mathrm{A} \beta 42 / \mathrm{A} \beta 40$ decreased; $A \beta 40$ and 42 polymerizations increased; and the resistance to proteolytic degradation with neprilysin increased [86, 91, 103, 104]. The TgAPParc mouse model carrying the E693G mutation (APP695) driven by the murine Thy1.2 promoter had 3to 7-fold higher expression of mutant human APP compared to endogenous mouse APP. Histological studies showed no NFTs, but strong intracellular $A \beta$ immunoreactivity in the hippocampus and cortex appeared at 3 months. A diffuse extracellular immunoreactivity appeared in some brain areas at 4 months; plaque-like structures in the subiculum appeared at 6 months; dense $\mathrm{A} \beta$ plaques with Congo red birefringence appeared in the subiculum at 9 months. Biochemical studies showed that $\mathrm{A} \beta 40$ and $\mathrm{A} \beta 42$ increased at 12 months. Memory defects were found at 15 months $[105,106]$.

\section{E693K (Italian) mutation}

The age of dementia onset is not available, the mean age of first brain hemorrhage was 49.9 years $(n=7)$, and the mean age of death was 60.0 years $(n=7)$. Brain imaging examinations (CT and MRI) showed cerebral hemorrhages, multi-infarct encephalopathy, and leukoaraiosis. The reported neuropathological characteristics included hemorrhages, no NFTs, amyloid plaques, and CAA $[102,107]$. Studies of APP processing in cellular models showed that the secreted $A \beta 38$ increased compared to the WT control; secreted A $\beta 40$ did not change; $A \beta 42$ and the ratio of $A \beta 42 / A \beta 40$ decreased; $\mathrm{A} \beta 42$ polymerization increased; and the resistance to proteolytic degradation with neprilysin increased [86, 91, 104]. There is no animal model available for this mutation.

\section{E693Q (Dutch) mutation}

The age of dementia onset is not available, the mean age of first brain hemorrhage was 53.7 years $(n=6)$, and the mean age of death was 57.9 years $(n=11)$. Brain imaging examinations (CT and MRI) showed cerebral hemorrhages. The reported neuropathological characteristics included hemorrhages, no NFTs, amyloid plaques, and CAA [102, 108-114]. Studies of APP processing in cellular models showed that the total secreted $A \beta$ and $A \beta 38$ did not change compared to the WT 
control; secreted $A \beta 40$ and $A \beta 42$ decreased; the ratio of $\mathrm{A} \beta 42 / \mathrm{A} \beta 40$ decreased; $A \beta 40$ polymerization increased; and the resistance to proteolytic degradation with neprilysin increased $[86,91,104]$. The APP Dutch mouse model carries the E693Q mutation (APP 751) driven by the murine Thy 1 promoter. Histological studies showed no NFTs and no amyloid plaques. CAA appeared at 22 months; activation of microglia and astrocytes appeared at 29 months; hemorrhage occurred at 29 months [115]. There is another transgenic mouse model carrying the E693Q mutation (APP751) driven by the murine Thy 1 promoter. Histological studies showed no NFTs and no amyloid plaques. Intraneuronal $A \beta$ was detected at 2 months; intraneuronal lysosomal accumulation of CTFs and lysosomal abnormality appeared at 12 months; CAA appeared at 12 months; loss of cholinergic neurons and GABAergic interneurons were found at 12 months; activation of microglia and astrocytes appeared at 12 months $[116,117]$.

\section{D694N (Iowa) mutation}

The mean age of dementia onset was 58.3 years $(n=7)$, the mean age of first brain hemorrhage was 43.8 years $(n=9)$, and the mean age of death was 65.3 years $(n=11)$. Brain imaging examinations (CT and MRI) showed cerebral hemorrhages. The reported neuropathological characteristics included NFTs, amyloid plaques, CAA, and astrocyte activation [118-122]. Studies of APP processing in cellular models showed that $\alpha$-CTF, total secreted $A \beta, A \beta 38, A \beta 40, A \beta 42$, and the ratio of $\mathrm{A} \beta 42 / \mathrm{A} \beta 40$ all unchanged compared to the WT control; $A \beta 40$ and $A \beta 42$ polymerization increased [86, 123]. There is no animal model available for this mutation.

\section{T714I (Austrian) mutation}

The mean age of onset was 34.0 years $(n=3)$, and the mean age of death was 46.3 years $(n=3)$. The reported neuropathological characteristics included NFTs, amyloid plaques, CAA, activation of microglia and astrocytes, and neuronal loss [124-127]. Studies of APP processing in cellular models showed that the intracellular $\mathrm{A} \beta, \alpha$ - and $\beta$-CTF levels increased compared to the WT control; secreted $A \beta 40$ decreased; $A \beta 42$ and the ratio of A $\beta 42 / A \beta 40$ increased [125-127]. The heterozygous APPAu5 mouse model carrying the T714I mutation (APP695) driven by the PDGF promoter showed expression levels of one-tenth of endogenous mouse APP levels. Brain volumes of APP-Au5 mice were significantly reduced on volumetric MRI at 12 months. Histological studies showed no NFTs and no amyloid plaques, but intraneuronal $\mathrm{A} \beta$ was observed in the perikaryon of the pyramidal neurons of the subiculum and of the CA1 and
CA2 hippocampal regions at 6 months. Neuronal loss was not found. Memory defects were not found [128].

\section{V715A (German) mutation}

The mean age of onset was 50 years $(n=5)$, and the mean age of death was not available. Brain imaging examination (PET) showed parieto-occipital hypometabolism. Neuropathological reports are not available $[129,130]$. Studies of APP processing in cellular models showed that $\alpha$ - and $\beta$-CTF levels were comparable to those in WT controls; secreted $A \beta 40$ decreased; secreted $A \beta 42$ and the ratio of $A \beta 42 / A \beta 40$ increased [127, $129,131]$. There is no animal model available for this mutation.

\section{V715M (French) mutation}

The mean age of onset was 47.8 years $(n=5)$, and the mean age of death was 55.8 years $(n=5)$. Brain imaging examinations (MRI and PET) showed cortical atrophy and hypometabolism. Neuropathological reports are not available [53, 132]. Studies of APP processing in cellular models showed that intracellular $A \beta$ decreased compared to WT control; $\alpha$-CTF level increased; $\beta$-CTF levels remained constant; total secreted $A \beta$ and $A \beta 40$ decreased; secreted $A \beta 42$ and the ratio of $A \beta 42 / A \beta 40$ increased [53, $127,131]$. There is no animal model available for this mutation.

\section{I716F (Iberian) mutation}

The mean age of onset was 36.0 years $(n=4)$, and the mean age of death was 36.7 years $(n=3)$. Brain imaging examinations (MRI and SPECT) showed cortical atrophy and cerebral blood flow reduction. The reported neuropathological characteristics included NFTs, amyloid plaques, CAA, activation of microglia and astrocytes, neuronal loss, and Lewy bodies [133-135]. Studies of APP processing in cellular models showed that the membrane-associated APP increased compared to the WT control; $\beta$-CTF increased; total secreted $A \beta$ decreased; $A \beta 38$ did not change; $A \beta 40$ decreased; $A \beta 42$ and the ratio of $A \beta 42 / A \beta 40$ increased $[126,134,136]$. There is no animal model available for this mutation.

\section{I716T mutation}

Only one case was reported, the age of onset was 36.0 years, and the age of death was 43 years. Neuropathological reports are not available [137]. Studies of APP processing in cellular models showed that the levels of membrane-associated APP and $\beta$-CTF did not change compared to the WT control; total secreted A $\beta$ did 
not change; $A \beta 38$ increased; $A \beta 40$ decreased; $A \beta 42$ and the ratio of $A \beta 42 / A \beta 40$ increased [136]. There is no animal model available for this mutation.

\section{I716V (Florida) mutation}

The mean age of onset was 52.7 years $(n=3)$, and the mean age of death was $60.0(n=1)$. Brain imaging examination (MRI) showed cortical atrophy. Neuropathological reports are not available [138]. Studies of APP processing in cellular models showed that the levels of membraneassociated APP did not change compared to the WT control; $\alpha$-CTF levels decreased; $\beta$-CTF levels remained constant; total secreted $\mathrm{A} \beta$ did not change; $\mathrm{A} \beta 38$ increased; $A \beta 40$ did not change; $A \beta 42$ and the ratio of $\mathrm{A} \beta 42 / \mathrm{A} \beta 40$ increased $[127,136,138]$. There is no animal model for this mutation.

\section{V717F (Indiana) mutation}

The mean age of onset was 42.1 years $(n=14)$, and the mean age of death was 47.9 years $(n=14)$. The reported neuropathological characteristics included NFTs, amyloid plaques, CAA [46, 139-142]. Studies of APP processing in cellular models showed that the $\alpha$-CTF level increased compared to the WT control; $A \beta 40$ decreased; $A \beta 42$ and the ratio of $A \beta 42 / A \beta 40$ increased [104, 126, 143-146]. The PDAPP (line 109) mouse model carrying the V717F (containing APP introns 6-8, allowing expression of mRNAs for human APP695, 751, 770) mutation driven by the platelet-derived growth factor (PDGF)- $\beta$ promoter had 10-fold expression of mutant human APP compared to endogenous mouse APP. Histological studies showed no NFTs, but phosphorylated tau was found in dystrophic neurites at 14 months. Amyloid plaques appeared in the cortex and hippocampus at 6 months; activation of microglia and astrocytes appeared at 13 months; synaptic loss was found in the dentate gyrus at 13 months. Biochemical studies showed that the total $A \beta$ (mainly A 442 ) concentration in the hippocampus was 500-fold greater at 18 months than at 4 months. Memory defects were found at 3 months [147-149].

\section{V717G mutation}

The mean age of onset was 56.0 years $(n=15)$, and the mean age of death was 60.7 years $(n=5)$. Brain imaging examination (MRI) showed cortical atrophy. The reported neuropathological characteristics included NFTs, amyloid plaques, and CAA [150-154]. Studies of APP processing in cellular models showed that the level of $\alpha$-CTF decreased compared to the WT control; $A \beta 40$ decreased; $A \beta 42$ and the ratio of $A \beta 42 / A \beta 40$ increased $[144,145]$. There is no animal model available for this mutation.

\section{V717I (London) mutation}

The mean age of onset was 50.2 years $(n=54)$, and the mean age of death was 62.1 years $(n=53)$. The reported neuropathological characteristics included NFTs, amyloid plaques, CAA, and Lewy bodies [46, 145, 155-162]. Studies of APP processing in cellular models showed that the intracellular $A \beta 40$ increased compared to the WT control; the levels of membrane associated APP, $\alpha-\mathrm{CTF}$, $\beta$-CTF all increased; total secreted $A \beta$ decreased; $A \beta 38$ increased; $A \beta 40$ decreased; $A \beta 42$ and the ratio of $\mathrm{A} \beta 42 / \mathrm{A} \beta 40$ increased $[48,89,126,127,134,138,144-$ $146,163,164]$. The APP(V717I) mouse model carrying the V717I mutation (APP695) driven by the murine Thy 1 promoter had 5-fold greater expression of mutant human APP compared to endogenous mouse APP. Histological studies showed no NFTs, but dystrophic neurites containing hyperphosphorylated tau appeared at 16 months. Amyloid plaques appeared in the cortex and subiculum at 10 months; CAA appeared at 15 months; activation of microglia appeared at 10 months; neuronal loss was not found. Memory defects were found at 6 months $[165,166]$. The APP(V642I)KI mouse model was generated by knocking the V717I mutation into exon 17 of the mouse APP gene using homologous recombination and the Cre-loxP system. The levels of APP expression in heterozygous mutant mice were similar to those of endogenous APP in WT mice. Histological studies showed no NFTs, no amyloid plaques, and no neuronal loss. A biochemical study showed that the ratio of A $\beta 42 / A \beta 40$ increased at 29 months. Memory defects were found at 27 months [167].

\section{V717L (Indiana-2) mutation}

The mean age of onset was 44.2 years $(n=28)$, and the mean age of death was 57.3 years $(n=17)$. Brain imaging examinations (MRI and SPECT) showed cortical atrophy and reduced cerebral blood flow. The reported neuropathological characteristics included NFTs and amyloid plaques $[140,168-173]$. Studies of APP processing in cellular models showed that the $\alpha$ - and $\beta$ CTF levels increased compared to the WT control; $A \beta 40$ decreased; $A \beta 42$ and the ratio of $A \beta 42 / A \beta 40$ increased [127]. There is no animal model available for this mutation.

\section{L723P (Australian) mutation}

The mean age of onset was 53.6 years $(n=5)$. One case died at age 53.0. Brain imaging examinations (CT) showed cortical atrophy. Neuropathological reports are not available. Studies of APP processing in cellular models showed that $A \beta 42$ and the ratio of $A \beta 42 / A \beta 40$ 
increased compared to the WT control $[46,174]$. There is no animal model available for this mutation.

\section{K724M mutation}

The mean age of onset was 46.6 years $(n=5)$, and the mean age of death was 54.3 years $(n=3)$.

Brain imaging examination (MRI) showed cortical atrophy. Neuropathological reports are not available. Studies of APP processing in cellular models showed that A $\beta 40$ did not change compared to WT control; $A \beta 42$ and the ratio of $A \beta 42 / A \beta 40$ increased [175]. There is no animal model available for this mutation.

\section{K724N (Belgian) mutation}
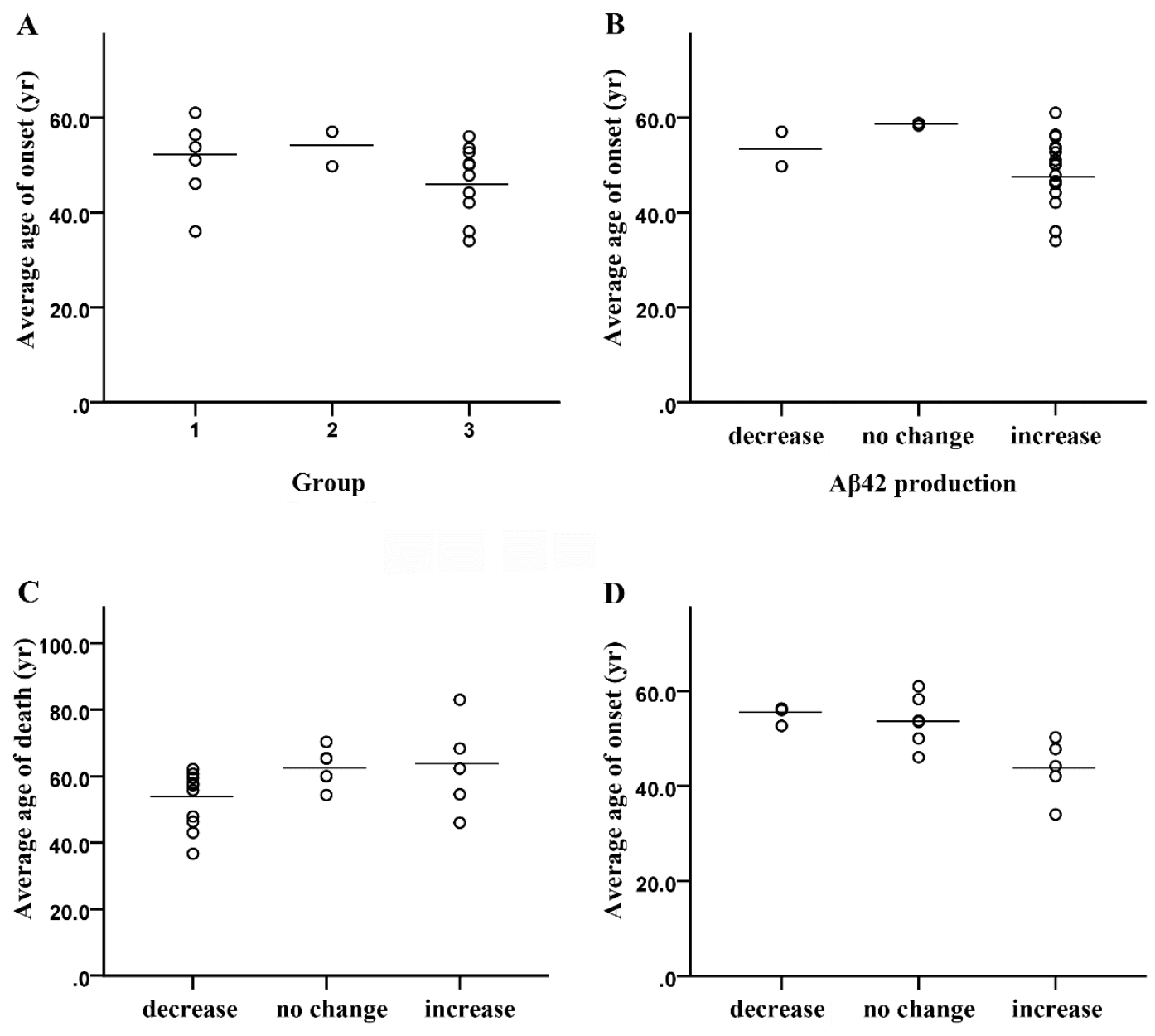

A $\beta 40$ production
The mean age of onset was 53.5 years $(n=2)$, and the mean age of death was 57.5 years $(n=2)$. One case suffered an aneurysmal subarachnoid hemorrhage at age 50 years. Brain imaging examination (PET) showed cortical hypometabolism and increased $A \beta$ deposition compared to control individuals. Neuropathological reports are not available. Studies of APP processing in cellular models showed that the $\alpha$ - and $\beta$-CTF levels did not change compared to the WT control; $A \beta 38$ increased; $A \beta 40$ decreased; $A \beta 42$ and the ratio of $A \beta 42 / A \beta 40$ increased [163]. There is no animal model available for this mutation.

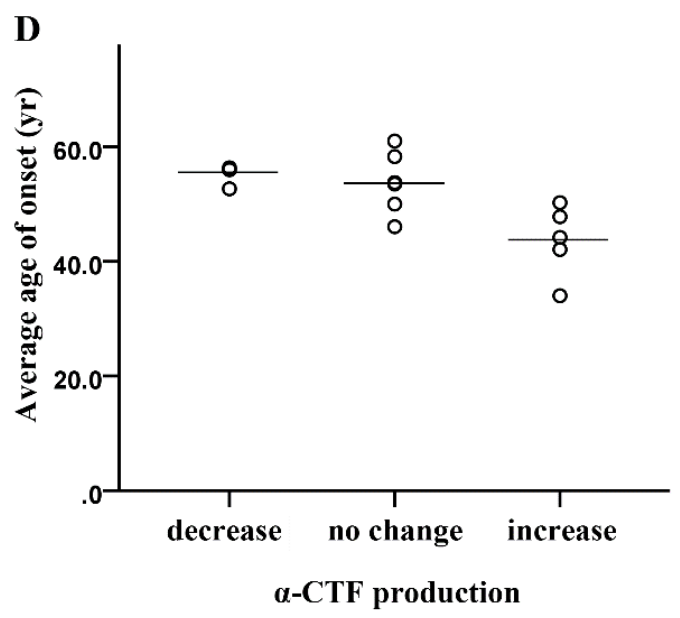

Figure 1. The correlation analysis. (A) The average age of $\mathrm{AD}$ onset in the three mutation Groups [8]. (B) Increased $\mathrm{A} \beta 42$ production tends to have an earlier age of $\mathrm{AD}$ onset $(\mathrm{r}=-0.328, \mathrm{p}=0.127)$. (C) $\mathrm{A} \beta 40$ production has a significantly positive correlation with age of death $(\mathrm{r}=0.440, \mathrm{p}=0.041)$. (D) The intracellular $\alpha$-CTF production has a significantly negative correlation with age of $\mathrm{AD}$ onset $(\mathrm{r}=-0.661, \mathrm{p}=0.010)$. Bars represent the mean value of each group. 


\section{Summary and discussion}

\section{The effects of $A \beta 42$ and $A \beta 40$}

According to the patterns of total $A \beta, A \beta 40, A \beta 42$ secreted from cellular models, Hunter and Brayne divided these mutations into three groups: Group 1 shows increases in total secreted $\mathrm{A} \beta, \mathrm{A} \beta 40, \mathrm{~A} \beta 42$ and the ratio of $\mathrm{A} \beta 42 / \mathrm{A} \beta 40$, and includes KM670/671NL, A673V, D678N, E682K, K687N, and A692G; Group 2 shows reductions in total secreted $A \beta, A \beta 40, A \beta 42$ and the ratio of $A \beta 42 / A \beta 40$, and includes E693del, E693G, E693K, and E693Q; Group 3 shows reductions in total secreted $A \beta$ and $A \beta 40$ combined with increased $A \beta 42$ and the ratio of $\mathrm{A} \beta 42 / \mathrm{A} \beta 40$, and include T714I, V715A, V715M, I716F, I716V, V717F, V717G, V717I, V717L, and $\mathrm{K} 724 \mathrm{~N}$ [8]. The average age of AD onset in Group 1 (6 mutations) is $50.7 \pm 8.8$ years (mean $\pm \mathrm{SD}$ ), in Group 2 (2 mutations) is $53.4 \pm 5.1$ years, and in Group 3 (10 mutations) is $46.6 \pm 7.4$ years (Fig. 1). Although one-way ANOVA does not show significant differences among the three groups, Group 3 (A $\beta 42$ increases only) has a tendency toward an earlier average age of AD onset, and Group 2 (decreases in all $A \beta s$ ) has a later age of $A D$ onset.

To reveal the correlation between clinical and neuropathological data as well as the features of mutant APP processing in cellular models, Pearson correlation analyses were performed with IBM SPSS software. The appearance of certain pathological features (such as NFTs, amyloid plaques, CAA, etc.) was set as 1, and no appearance was set as 0. An increase in APP proteolytic products compared to the WT control was set as 1 , no change as 0 , and a decrease as -1 . The analysis showed that increased $A \beta 42$ production tends to have an earlier age of $\mathrm{AD}$ onset $(\mathrm{r}=-0.328, \mathrm{p}=0.127)$. $\mathrm{A} \beta 40$ production has a significantly positive correlation with age of death $(\mathrm{r}=0.440, \mathrm{p}=0.041)$ and an insignificantly positive correlation with age of $\mathrm{AD}$ onset $(\mathrm{r}=0.334, \mathrm{p}=0.128)$ (Fig. 1). It has been widely accepted that the longer form, $\mathrm{A} \beta 42$, is the most amyloidogenic form of the peptide and plays a critical role in AD pathogenesis [176], whereas the shorter $A \beta 40$, which is predominantly associated with CAA, may have a protective effect against $\mathrm{A} \beta 42$. Both in vivo and in vitro studies have confirmed this protective effect and showed short $A \beta s$, such as $A \beta 38$ and $A \beta 40$, could directly interact with $A \beta 42$ to interfere with either the aggregate structure or the kinetics of aggregation to attenuate the deleterious effects of $\mathrm{A} \beta 42$ [177, 178].

The correlation analysis also shows that $A \beta 42$ production and the ratio of $A \beta 42 / A \beta 40$ have significantly positive correlations with the presence of NFTs $(r=0.740$, $p=0.004$ and $r=0.679, p=0.011$, respectively). The results suggest that the accumulation of extracellular A $\beta 42$ could trigger the formation of intracellular NFTs.
As summarized in review papers, clinical studies found that NFTs appeared following amyloid deposition in Down syndrome (carrying an extra copy of APP) and an increase in CSF tau following amyloid deposition in early onset cases with inherited mutations of APP and presenilin. Both cellular and mouse models suggested that the damaging effects of extracellular $A \beta$ on neurons occur through the intracellular tau protein [176, 179-182]. The fact that the progress of dementia symptoms in $A D$ is highly correlated with the development of NFTs rather than amyloid deposition also supports this view [25, 183]. The appearance of NFTs is dependent on the susceptibility of neurons [184-186]. The role of proteasome and autophagy-lysosome systems are to maintain the balance between protein synthesis and protein clearance. Proteasomal stress, which occurs in AD and mild cognitive impairment brains, can alter this balance. Farizatto et al. found that extracellular Aß42 could damage the function of proteasome and autophagylysosome systems in cultured hippocampal slices, causing an increase in tau phosphorylation [187].

\section{The effects of intracellular APP proteolytic products}

Although the APP mutations in Group 2 can cause decreases in $A \beta$ production in cellular models compared to WT APP, patients with E693G, E693K, and E693Q mutations still showed extracellular amyloid deposition, $\mathrm{CAA}$ and typical clinical features of $\mathrm{AD}$. This condition is probably related to the increased $A \beta$ polymerization and resistance to proteolytic degradation for Group 2 mutations. Additionally, cellular model studies indicated that intracellular $A \beta$ increased in Group 2 mutations, especially in cases in which the E693del mutation did not have amyloid deposition but showed progressive cognitive defects $[93,94]$. It has been suggested that intracellular $\mathrm{A} \beta$ has a critical role in $\mathrm{AD}$ [95].

Among the $15 \mathrm{Tg}$ animal models discussed in this review, $11 \mathrm{Tg}$ mouse lines with $\mathrm{A} \beta$ deposition completed the cognitive examinations, in which $9(81.8 \%) \mathrm{Tg}$ mouse lines (APP23, TSA10, APPSwe-NSE, Tg2576, APP E693 $\Delta$-Tg, OSK-KI, PDAPP line 109, APP(V717I), and APP(V642I)KI) showed that memory defects appeared prior to $A \beta$ deposition. Only $2(18.2 \%) \mathrm{Tg}$ mouse lines (TgAPParc and APPSwe) showed memory defects after $A \beta$ deposition or no memory defects after $A \beta$ deposition. This fact suggests that amyloid plaque may not be directly responsible for neuronal dysfunction. On the other hand, $5 \mathrm{Tg}$ mouse lines that had completed the cognitive examinations were examined for intracellular $A \beta$, and 4 $(80.0 \%)$ of them (TAS10, APPSw-NSE, APP E693 $\Delta$-Tg, TgAPParc) showed that intracellular $A \beta s$ appeared in advance of or at the same time as memory defects, only 1 (20.0\%) Tg mouse line (OSK-KI) showed intracellular 
A $\beta$ s appeared after memory defects. These results may be explained by the accumulation of intracellular $A \beta$ rather than extracellular $A \beta$ deposition causing neuronal dysfunction in advance.

A large number of studies on post-mortem brain samples with $\mathrm{AD}$ and Down syndrome have provided evidence for the presence of $A \beta$ within neurons. Studies have shown that the accumulation of intraneuronal $A \beta$ is an early event in the progression of $\mathrm{AD}$, preceding the formation of extracellular A $\beta$ deposits [188]. A neuropathological study on AD cases with the E693G mutation suggested that intracellular $A \beta$ oligomers are more neurotoxic than extracellular $A \beta$ deposition [100]. A transgenic mouse model showed that the extensive neuronal loss in the hippocampal areas CA1 and CA2 correlated with strong accumulation of intraneuronal $A \beta$, but not with extracellular A $\beta$ deposition [189].

Furthermore, the correlation analysis shows that the increase in intracellular $\alpha$-CTF has a significantly negative correlation with the age of $\mathrm{AD}$ onset $(\mathrm{r}=-0.661$, $\mathrm{p}=0.010$ ), and $\beta$-CTF also shows a tendency toward a negative correlation with the age of $\mathrm{AD}$ onset $(\mathrm{r}=-0.341$, $\mathrm{p}=0.196$ ) (Fig. 1). In other words, the results suggest that CTFs might cause neuronal dysfunction. Pera et al. found that the $\beta$-CTF level in the postmortem brain samples of EOFAD ( 2 cases with APP mutation and 8 cases with PS 1 mutations) was significantly higher than in age-matched controls and sporadic AD. Increases in $\alpha$ - and $\beta$-CTF were also observed by Western blot in sporadic AD cases compared to controls [190]. Lahiri et al. found that immunohistochemical staining for CTFs appeared in the perinuclear region, amyloid plaques, neurites and NFTbearing neurons, which provided evidence for the key role of CTFs in the pathogenesis of AD [191]. The level of 25$\mathrm{kDa}$ CTF in cerebrospinal fluid was higher in AD with PS1 mutations, in Down syndrome, and in sporadic AD subjects [192]. The neurotoxic effects of CTF accumulation have already been reported in cellular and animal models. For example, $\alpha-\mathrm{CTF}$ accumulation in Chinese hamster ovary cells could trigger impairment of the cAMP/PKA/CREB pathway (involved in synaptic plasticity and memory) without $A \beta$ involvement [193]. The accumulation of $\beta$-CTF could induce dysfunction of endosomes in Down syndrome and AD [194]. APP Cterminal fragments AICD exerted neurotoxicity in PC12 cells and primary neurons by inducing the expression of glycogen synthase kinase $3 \beta$, causing tau phosphorylation and leading to apoptosis [195]. $\beta$-CTF was the earliest APP proteolytic product in the hippocampal neurons of $3 \times T g-A D$ mice, which suggested that $\beta$-CTF was an initiator of the neurodegenerative process in this mouse model [196]. Schettini et al. summarized the perturbation of the physiological activities of CTFs and AICD as an alternative perspective for neurodegeneration [197].
The ER is the main organelle involved in protein folding and secretion. During $\mathrm{AD}$, the continuous accumulation of hyperphosphorylated tau and intraneuronal APP products within the ER lumen can cause chronic or irreversible ER stress, which may lead to neuronal apoptosis through unfolded protein response (UPR) [198]. Other organelle stress, including of the Golgi, mitochondrial, endosomes, and the proteasome and autophagy-lysosome, also has been linked to the intracellular accumulation of abnormal proteins and disturbance of signal pathways in neurodegenerative diseases, which could trigger neuronal cell death by a variety of endogenous suicide pathways [199-203]. Taken together, these data suggest that the intraneuronal accumulation of NFTs, A $\beta$ s, and CTFs might provoke organelle stress and lead to neurodegeneration in $\mathrm{AD}$.

\section{An amyloid hypothesis}

Hypotheses based on genetic evidence include the wellknown amyloid cascade hypothesis $(\mathrm{ACH})$, the presenilin hypothesis (PSH) and the more recent APP matrix approach (AMA) [8]. However, increasing evidence and questions have perforated some arguments behind these hypotheses, which will be explored. The amyloid cascade hypothesis posits the "cascade" of cellular events as stemming directly from the toxicity of amyloid beta, including NFT aggregation and neuronal loss. Many scientific findings contradict this observation, instead citing NFT aggregation or other malfunctions of processing enzymes. Specifically, AD-associated pathologies, such as amyloid plaques, can be present in individuals without any apparent cognitive impairment [204, 205]. Recent neuroimaging studies also suggested that amyloid plaques may not be directly responsible for neuronal dysfunction [206, 207]. Furthermore, neurodegeneration in $\mathrm{AD}$ may be independent of extracellular $A \beta$ and oligomers, and the toxic effects observed in cellular and Tg animal models overexpressing exogenous APP may not apply to situations for most AD patients without overexpression of APP [208]. The analysis in this paper shows a weak negative correlation between increased $A \beta 42$ production and the age of $\mathrm{AD}$ onset $(r=-0.328, p=0.127)$, which might indicate that $\mathrm{A} \beta 42$ production is an indirect cause of $\mathrm{AD}$ onset.

The presenilin hypothesis explains amyloid beta generation and the subsequent neuronal loss in terms of partial loss of function of the presenilin $\gamma$-secretase [209]. However, the majority of $\mathrm{AD}$ cases do not involve the dysfunction of $\gamma$-secretase; therefore, this theory is not viable to explain the general pathogenesis of $\mathrm{AD}[8,176]$.

The APP matrix approach attempts to view the APP proteolytic system holistically, suggesting that a dynamic balance of APP products is necessary for proper neuronal 
function. It explains that although familial AD genetic mutations can alter the balance of the APP proteolytic system, other systems, e.g., cholesterol homeostasis, immune signaling, and synaptic plasticity, can alter this balance, which can lead to multiple disease pathways. Despite the scope of this hypothesis, it remains a potpourri of ideas that does not completely explain certain observations, such as how $A \beta$-associated pathology may be present in those without cognitive impairment.

Based on our analysis and the fact that amyloid plaque burden correlates much less well with degree of cognitive impairment than NFTs counts do, we propose the Snowball Hypothesis, a theory encompassing observed phenomena, as the $\mathrm{ACH}$ attempted to do with the $A \beta$ peptide, and retaining the scope attempted by the AMA. This theory posits that the accumulation of extracellular $A \beta 42$ does not directly cause neuronal death or dysfunction - instead, it induces stress in various protein-handling organelles such as the ER, the Golgi/TGN, and endosomes. This gradual cellular stress increases the retention of misfolded proteins, such as the hyperphosphorylated tau protein or aggregates of the $\alpha$ synuclein protein. The NFTs and Lewy bodies subsequently appear in neurons depending on their susceptibility. In addition, intracellular APP proteolytic products (CTFs and $A \beta s$ ) also aggravate the organelle stress. With the abnormal intracellular protein accumulation, vulnerable neurons slowly lose function and finally die, resembling abnormal protein "snowball" formations both inside and outside of neurons.

Several key questions regarding the amyloid hypothesis were raised in Selkoe and Hardy's review paper [176]. We try to provide a perspective for answering them with the principles of the Snowball Hypothesis.

1 . What are the toxic species of $A \beta$ and tau?

The accumulation of $A \beta$ and tau protein occurs over a relatively long period of time, as they can be retained for two decades without noticeable cognitive decline. Therefore, we would like to say that they are an increasing burden that stresses neuronal organelles rather than being "toxic".

2. What is the connection between $A \beta$ and tangle pathology? Is it direct and cell autonomous or does it involve non-neuronal cells?

Extracellular A $\beta 42$ and intracellular APP proteolytic products (CTFs and $A \beta s$ ) cause organelle stress and abnormal activation of kinases, which induce hyperphosphorylation of tau and subsequently lead to the formation of NFTs.

3. What is the mechanism of pathology spread and does understanding this spread provide therapeutic opportunities?

The spread of pathology (mainly for NFTs) is dependent on the predisposing factors (CTFs and A $\beta s$ ) and the susceptibility of neurons. Therapeutic opportunities rely on elimination of abnormal APP metabolism and relief of organelle stress in neurons.

4. What is the function of APP and does A $\beta$ have a function?

We believe that the major function of APP is as an adhesion molecule for synaptic formation and neurite growth. A $\beta$ s are only metabolic waste products of APP.

5. GWA studies have identified cholesterol metabolism, the innate immune system, and endosomal vesicle recycling as important pathogenic processes in $\mathrm{AD}$ : how do these relate to each other?

These processes all relate to the extracellular and intracellular clearance of abnormal protein accumulation, including $A \beta$ and hyperphosphorylated tau.

\section{Concluding remarks}

Our summarized data from APP missense mutation studies have painted a clear picture, in which intraneuronal NFTs caused by the accumulation of extracellular $A \beta 42$ and the increase in intraneuronal APP proteolytic products (CTFs and $A \beta s$ ) could cause organelle stress in neurons, leading to neurodegeneration in $\mathrm{AD}$. We must emphasize that the published clinical and neuropathological data related to APP missense mutations are incomplete. For some mutations (A673T, A673V, D678H, and I716T), only one clinical case was reported, and many mutations (D678H, D678N, E682K, K687N, E693del, V715A, V715M, I716T, I716V, L723P, and K724M) lacked neuropathological reports. The experimental protocols and reports in the cellular and $\mathrm{Tg}$ animal models exhibited large variations, including in the cell types, gene delivery systems, treatment procedures, methods and antibodies to investigate APP proteolytic fragments [8]. Therefore, a collection containing additional clinical cases with FAD, standardized experimental protocols for cellular and $\mathrm{Tg}$ animal models, and the systematic measurement of APP proteolytic fragments for all known pathogenic mutations with standardized reporting formats would help to uncover the mechanism of pathogenesis caused by APP mutations [8]. Nevertheless, this preliminary analysis still provides support for future investigation of the role of extracellular $\mathrm{A} \beta 42$ and intracellular APP proteolytic products. We believe that the elimination of abnormal APP proteolytic product accumulation and the relief of organelle stress for neurons would be practical treatment strategies. Secretase inhibitors, $A \beta$ antibodies, attracting microglia to sites of $A \beta$ accumulation [210], upregulation of proteasomes, and siRNA interference [211] also remain options. Relieving organelle stress and burden warrants further investigation. Recent developments include engineering small-molecule inhibitors of kinases such as CDK5 that can provide 
avenues for preventing Golgi stress and tau aggregation. Additionally, stimulating the release of intracellular $\mathrm{A} \beta$ localized in late endosomes or cellular compartments can prevent inappropriate interactions with organelles [212]. In general, combinations of these treatment strategies may provide the optimal methods to prevent and treat $\mathrm{AD}$.

\section{Acknowledgements}

This study was supported by the Washington Institute for Health Sciences grant (G20170901).

\section{Conflict of Interest}

No conflict of interest is declared.

\section{References}

[1] Hebert LE, Weuve J, Scherr PA, Evans DA (2013). Alzheimer disease in the United States (2010-2050) estimated using the 2010 Census. Neurology, 80:1778-83.

[2] Prince M, Comas-Herrera A, Knapp M, Guerchet M, Karagiannidou M. World Alzheimer Report 2016: Improving healthcare for people living with dementia. Coverage, quality and costs now and in the future. London: Alzheimer's Disease International (ADI); 2016.

[3] Reitz C (2012). Alzheimer's disease and the amyloid cascade hypothesis: a critical review. Int J Alzheimers Dis, 2012:369808.

[4] Bird TD (1993-2018). Alzheimer Disease Overview. In: Adam MP, Ardinger HH, Pagon RA, Wallace SE, Bean LJH, Stephens K, et al., editors. GeneReviews ${ }^{\circledR}$ [Internet]. Seattle, University of Washington.

[5] Kumar K, Kumar A, Keegan RM, Deshmukh R (2017). Recent advances in the neurobiology and neuropharmacology of Alzheimer's disease. Biomed Pharmacother, 98:297-307.

[6] Hardy JA, Higgins GA (1992). Alzheimer's disease: the amyloid cascade hypothesis. Science, 256:184-5.

[7] Shen J, Kelleher RJ (2007). The presenilin hypothesis of Alzheimer's disease: evidence for a loss-of-function pathogenic mechanism. Proc Natl Acad Sci USA, 104:403-409.

[8] Hunter S, Brayne C (2018). Understanding the roles of mutations in the amyloid precursor protein in Alzheimer disease. Mol Psychiatry, 23:81-93.

[9] Iqbal K, Liu F, Gong CX (2016). Tau and neurodegenerative disease: the story so far. Nat Rev Neurol, 12:15-27.

[10] Heppner FL, Ransohoff RM, Becher B (2015). Immune attack: the role of inflammation in Alzheimer disease. Nat Rev Neurosci, 16:358-372.]

[11] Cheignon C, Tomas M, Bonnefont-Rousselot D, Faller P, Hureau C, Collin F (2018). Oxidative stress and the amyloid beta peptide in Alzheimer's disease. Redox Biol, 14:450-464.
Pei L, Wallace DC (2018). Mitochondrial Etiology of Neuropsychiatric Disorders. Biol Psychiatry, 83:722730.

Hetz C, Saxena S (2017). ER stress and the unfolded protein response in neurodegeneration. Nat Rev Neurol, 13:477-491.

Neth BJ, Craft S (2017). Insulin Resistance and Alzheimer's Disease: Bioenergetic Linkages. Front Aging Neurosci, 9:345.

Wong BX, Hung YH, Bush AI, Duce JA (2014). Metals and cholesterol: two sides of the same coin in Alzheimer's disease pathology. Front Aging Neurosci, 6:91.

Hernández-Ortega K, Quiroz-Baez R, Arias C (2011). Cell cycle reactivation in mature neurons: a link with brain plasticity, neuronal injury and neurodegenerative diseases? Neurosci Bull, 27:18596.

[17] Sandbrink R, Masters CL, Beyreuther K (1996). APP gene family. Alternative splicing generates functionally related isoforms. Ann N Y Acad Sci, 777:281-7.

[18] Menéndez-González M, Pérez-Pinera P, MartínezRivera M, Calatayud MT, Blázquez Menes B (2005). APP processing and the APP-KPI domain involvement in the amyloid cascade. Neurodegener Dis, 2:277-83.

[19] Zhang YW, Thompson R, Zhang H, Xu H (2011). APP processing in Alzheimer's disease. Mol Brain, 4:3.

[20] Müller UC, Deller T, Korte M (2017). Not just amyloid: physiological functions of the amyloid precursor protein family. Nat Rev Neurosci, 18:281298.

[21] Müller UC, Zheng H (2012). Physiological functions of APP family proteins. Cold Spring HarbPerspect Med, 2:a006288.

[22] Taylor CJ, Ireland DR, Ballagh I, Bourne K, Marechal NM, Turner PR, et al. (2008). Endogenous secreted amyloid precursor protein-alpha regulates hippocampal NMDA receptor function, long-term potentiation and spatial memory. Neurobiol Dis, 31:250-60.

[23] Nikolaev A, McLaughlin T, O'Leary DD, TessierLavigne M (2009). APP binds DR6 to trigger axon pruning and neuron death via distinct caspases. Nature, 457:981-9.

[24] Haass C, Kaether C, Thinakaran G, Sisodia S (2012). Trafficking and proteolytic processing of APP. Cold Spring Harb Perspect Med, 2:a006270.

[25] Serrano-Pozo A, Frosch MP, Masliah E, Hyman BT (2011). Neuropathological alterations in Alzheimer disease. Cold Spring Harb Perspect Med, 1:a006189.

[26] Grundke-Iqbal I, Iqbal K, Tung YC, Quinlan M, Wisniewski HM, Binder LI (1986). Abnormal phosphorylation of the microtubule-associated protein tau (tau) in Alzheimer cytoskeletal pathology. Proc Natl Acad Sci U S A, 83:4913-7.

[27] Ingelsson M, Fukumoto H, Newell KL, Growdon JH, Hedley-Whyte ET, Frosch MP, et al. (2004). Early Abeta accumulation and progressive synaptic loss, 
gliosis, and tangle formation in AD brain. Neurology, 62:925-31.

[28] Braak H, Braak E (1991). Neuropathological staging of Alzheimer-related changes. Acta Neuropathol, 82:239-59.

[29] Schneider JA, Arvanitakis Z, Leurgans SE, Bennett DA (2009). The neuropathology of probable Alzheimer disease and mild cognitive impairment. Ann Neurol, 66:200-8.

[30] Bussière T, Gold G, Kövari E, Giannakopoulos P, Bouras C, Perl DP, et al. (2003). Stereologic analysis of neurofibrillary tangle formation in prefrontal cortex area 9 in aging and Alzheimer's disease. Neuroscience, 117:577-92.

[31] Morris M, Maeda S, Vossel K, Mucke L (2011). The many faces of tau. Neuron, 70:410-26.

[32] Serrano-Pozo A, Mielke ML, Gómez-Isla T, Betensky RA, Growdon JH, Frosch MP, et al. (2011). Reactive glia not only associates with plaques but also parallels tangles in Alzheimer's disease. Am J Pathol, 179:1373-84.

[33] Gómez-Isla T, Hollister R, West H, Mui S, Growdon JH, Petersen RC, et al. (1997). Neuronal loss correlates with but exceeds neurofibrillary tangles in Alzheimer's disease. Ann Neurol, 41:17-24.

[34] Scheff SW, Price DA, Schmitt FA, DeKosky ST, Mufson EJ (2007). Synaptic alterations in CA1 in mild Alzheimer disease and mild cognitive impairment. Neurology, 68:1501-8.

[35] Hoozemans JJ, van Haastert ES, Nijholt DA, Rozemuller AJ, Eikelenboom P, Scheper W (2009). The unfolded protein response is activated in pretangle neurons in Alzheimer's disease hippocampus. Am J Pathol, 174:1241-51.

[36] Sasaki S (2010). Endoplasmic reticulum stress in motor neurons of the spinal cord in sporadic amyotrophic lateral sclerosis. J Neuropathol Exp Neurol, 69:346-55.

[37] Hamilton RL (2000). Lewy bodies in Alzheimer's disease: a neuropathological review of 145 cases using alpha-synuclein immunohistochemistry. Brain Pathol, 10:378-84.

[38] Lippa CF, Fujiwara H, Mann DM, Giasson B, Baba M, Schmidt ML, et al. (1998). Lewy bodies contain altered alpha-synuclein in brains of many familial Alzheimer's disease patients with mutations in presenilin and amyloid precursor protein genes. Am J Pathol, 153:1365-70.

[39] Di Fede G, Catania M, Morbin M, Rossi G, Suardi S, Mazzoleni G, et al. (2009). A recessive mutation in the APP gene with dominant-negative effect on amyloidogenesis. Science, 323:1473-7.

[40] Mullan M, Crawford F, Axelman K, Houlden H, Lilius L, Winblad B, et al. (1992). A pathogenic mutation for probable Alzheimer's disease in the APP gene at the N-terminus of beta-amyloid. Nat Genet, 1:345-7.

[41] Axelman K, Basun H, Winblad B, Lannfelt L (1994). A large Swedish family with Alzheimer's disease with a codon 670/671 amyloid precursor protein mutation.
A clinical and genealogical investigation. Arch Neurol, 51:1193-7.

Bogdanovic N, Corder E, Lannfelt L, Winblad B (2002). APOE polymorphism and clinical duration determine regional neuropathology in Swedish APP $(670,671)$ mutation carriers: implications for lateonset Alzheimer's disease. J Cell Mol Med, 6:199-214. Piras A, Collin L, Grüninger F, Graff C, Rönnbäck A (2016). Autophagic and lysosomal defects in human tauopathies: analysis of post-mortem brain from patients with familial Alzheimer disease, corticobasal degeneration and progressive supranuclear palsy. Acta Neuropathol Commun, 4:22.

[44] Thordardottir S, KinhultStåhlbom A, Almkvist O, Thonberg H, Eriksdotter $M$, Zetterberg $H$, et al. (2017). The effects of different familial Alzheimer's disease mutations on APP processing in vivo. Alzheimers Res Ther, 9:9.

[45] Julin P, Almkvist O, Basun H, Lannfelt L, Svensson L, Winblad B, et al. (1998). Brain volumes and regional cerebral blood flow in carriers of the Swedish Alzheimer amyloid protein mutation. Alzheimer Dis Assoc Disord, 12:49-53.

[46] Ryman DC, Acosta-Baena N, Aisen PS, Bird T, Danek A, Fox NC, et al. (2014). Symptom onset in autosomal dominant Alzheimer disease: a systematic review and meta-analysis. Neurology, 83:253-60.

[47] Lannfelt L, Bogdanovic N, Appelgren H, Axelman K, Lilius L, Hansson G, et al. (1994). Amyloid precursor protein mutation causes Alzheimer's disease in a Swedish family. Neurosci Lett, 168:254-6.

[48] Johnston JA, Cowburn RF, Norgren S, Wiehager B, Venizelos N, Winblad B, et al. (1994). Increased betaamyloid release and levels of amyloid precursor protein (APP) in fibroblast cell lines from family members with the Swedish Alzheimer's disease APP670/671 mutation. FEBS Lett, 354:274-8.

[49] De Strooper B, Simons M, Multhaup G, Van Leuven F, Beyreuther K, Dotti CG (1995). Production of intracellular amyloid-containing fragments in hippocampal neurons expressing human amyloid precursor protein and protection against amyloidogenesis by subtle amino acid substitutions in the rodent sequence. EMBO J, 14:4932-8.

[50] Martin BL, Schrader-Fischer G, Busciglio J, Duke M, Paganetti P, Yankner BA (1995). Intracellular accumulation of beta-amyloid in cells expressing the Swedish mutant amyloid precursor protein. J Biol Chem, 270:26727-30.

[51] McPhie DL, Lee RK, Eckman CB, Olstein DH, Durham SP, Yager D, et al. (1997). Neuronal expression of beta-amyloid precursor protein Alzheimer mutations causes intracellular accumulation of a C-terminal fragment containing both the amyloid beta and cytoplasmic domains. J Biol Chem, 272:24743-6.

Golde TE, Cai XD, Shoji M, Younkin SG (1993). Production of amyloid beta protein from normal amyloid beta-protein precursor (beta APP) and the 
mutated beta APPS linked to familial Alzheimer's disease. Ann N Y Acad Sci, 695:103-8.

[53] Ancolio K, Dumanchin C, Barelli H, Warter JM, Brice A, Campion D, et al. (1999). Unusual phenotypic alteration of beta amyloid precursor protein (betaAPP) maturation by a new Val-715 --> Met betaAPP-770 mutation responsible for probable early-onset Alzheimer's disease. Proc Natl Acad Sci U S A, 96:4119-24.

[54] Sturchler-Pierrat C, Abramowski D, Duke M, Wiederhold KH, Mistl C, Rothacher S, et al. (1997). Two amyloid precursor protein transgenic mouse models with Alzheimer disease-like pathology. Proc Natl AcadSci U S A, 94:13287-92.

[55] Calhoun ME, Wiederhold KH, Abramowski D, Phinney AL, Probst A, Sturchler-Pierrat C, et al. (1998). Neuron loss in APP transgenic mice. Nature, 395:755-6.

[56] Stalder M, Phinney A, Probst A, Sommer B, Staufenbiel M, Jucker M (1999). Association of microglia with amyloid plaques in brains of APP23 transgenic mice. Am J Pathol, 154:1673-84.

[57] Winkler DT, Bondolfi L, Herzig MC, Jann L, Calhoun ME, Wiederhold KH, et al. (2001). Spontaneous hemorrhagic stroke in a mouse model of cerebral amyloid angiopathy. J Neurosci, 21:1619-27.

[58] Reichwald J, Danner S, Wiederhold KH, Staufenbiel M (2009). Expression of complement system components during aging and amyloid deposition in APP transgenic mice. J Neuroinflammation, 6:35.

[59] Van Dam D, D'Hooge R, Staufenbiel M, Van Ginneken C, Van Meir F, De Deyn PP (2003). Agedependent cognitive decline in the APP23 model precedes amyloid deposition. Eur J Neurosci, 17:38896.

[60] Kelly PH, Bondolfi L, Hunziker D, Schlecht HP, Carver K, Maguire E, et al. (2003). Progressive agerelated impairment of cognitive behavior in APP23 transgenic mice. Neurobiol Aging, 24:365-78.

[61] Richardson JC, Kendal CE, Anderson R, Priest F, Gower E, Soden P, et al. (2003). Ultrastructural and behavioural changes precede amyloid deposition in a transgenic model of Alzheimer's disease. Neuroscience, 122:213-28.

[62] Philipson O, Hammarström P, Nilsson KP, Portelius E, Olofsson T, Ingelsson M, et al. (2009). A highly insoluble state of Abeta similar to that of Alzheimer's disease brain is found in Arctic APP transgenic mice. Neurobiol Aging, 30:1393-405.

[63] Lord A, Kalimo H, Eckman C, Zhang XQ, Lannfelt L, Nilsson LN (2006). The Arctic Alzheimer mutation facilitates early intraneuronal Abeta aggregation and senile plaque formation in transgenic mice. Neurobiol Aging, 27:67-77.

[64] Lord A, Philipson O, Klingstedt T, Westermark G, Hammarström P, Nilsson KP, et al. Observations in APP bitransgenic mice suggest that diffuse and compact plaques form via independent processes in Alzheimer's disease. Am J Pathol, 178:2286-98.
[65]

Borchelt DR, Ratovitski T, van Lare J, Lee MK, Gonzales V, Jenkins NA, et al. (1997). Accelerated amyloid deposition in the brains of transgenic mice coexpressing mutant presenilin 1 and amyloid precursor proteins. Neuron, 19:939-45.

[66] Savonenko AV, Xu GM, Price DL, Borchelt DR, Markowska AL (2003). Normal cognitive behavior in two distinct congenic lines of transgenic mice hyperexpressing mutant APP SWE. Neurobiol Dis, 12:194-211.

[67] Hwang DY, Cho JS, Lee SH, Chae KR, Lim HJ, Min $\mathrm{SH}$, et al. (2004). Aberrant expressions of pathogenic phenotype in Alzheimer's disease transgenic mice carrying NSE-controlled APPsw. Exp Neurol, 186:2032.

[68] Hsiao K, Chapman P, Nilsen S, Eckman C, Harigaya Y, Younkin S, et al. (1996). Correlative memory deficits, Abeta elevation, and amyloid plaques in transgenic mice. Science, 274:99-102.

[69] Lanz TA, Carter DB, Merchant KM (2003). Dendritic spine loss in the hippocampus of young PDAPP and Tg2576 mice and its prevention by the ApoE2 genotype. Neurobiol Dis, 13:246-53.

[70] Kero M, Paetau A, Polvikoski T, Tanskanen M, Sulkava R, Jansson L, et al. (2013). Amyloid precursor protein (APP) A673T mutation in the elderly Finnish population. Neurobiol Aging, 34:1518.e1-3.

[71] Jonsson T, Atwal JK, Steinberg S, Snaedal J, Jonsson PV, Bjornsson S, et al. (2012). A mutation in APP protects against Alzheimer's disease and age-related cognitive decline. Nature, 488:96-9.

[72] Zhang S, Wang Z, Cai F, Zhang M, Wu Y, Zhang J, et al. (2017). BACE1 Cleavage Site Selection Critical for Amyloidogenesis and Alzheimer's Pathogenesis. J Neurosci, 37:6915-6925.

Benilova I, Gallardo R, Ungureanu AA, Castillo Cano V, Snellinx A, Ramakers M, et al. (2014). The Alzheimer disease protective mutation A2T modulates kinetic and thermodynamic properties of amyloid- $\beta$ (A $\beta$ ) aggregation. J Biol Chem, 289:30977-89.

[74] Maloney JA, Bainbridge T, Gustafson A, Zhang S, Kyauk R, Steiner P, et al. (2014). Molecular mechanisms of Alzheimer disease protection by the A673T allele of amyloid precursor protein. J Biol Chem, 289:30990-1000.

[75] Giaccone G, Morbin M, Moda F, Botta M, Mazzoleni G, Uggetti A, et al. (2010). Neuropathology of the recessive A673V APP mutation: Alzheimer disease with distinctive features. Acta Neuropathol, 120:80312.

[76] Chen WT, Hong CJ, Lin YT, Chang WH, Huang HT, Liao JY, et al. (2012). Amyloid-beta (A $\beta)$ D7H mutation increases oligomeric $\mathrm{A} \beta 42$ and alters properties of $A \beta$-zinc/copper assemblies. PLoS One, 7:e35807.

[77] Lin YC, Wang JY, Wang KC, Liao JY, Cheng IH (2014). Differential regulation of amyloid precursor protein sorting with pathological mutations results in a distinct effect on amyloid-beta production. J Neurochem, 131:407-12. 
[78] Wakutani Y, Watanabe K, Adachi Y, Wada-Isoe K, Urakami K, Ninomiya H, et al. (2004). Novel amyloid precursor protein gene missense mutation $(\mathrm{D} 678 \mathrm{~N})$ in probable familial Alzheimer's disease. J Neurol Neurosurg Psychiatry, 75:1039-42.

[79] Hori Y, Hashimoto T, Wakutani Y, Urakami K, Nakashima K, Condron MM, et al. (2007). The Tottori (D7N) and English (H6R) familial Alzheimer disease mutations accelerate Abeta fibril formation without increasing protofibril formation. $\mathrm{J}$ Biol Chem, 282:4916-23.

[80] Ono K, Condron MM, Teplow DB (2010). Effects of the English (H6R) and Tottori (D7N) familial Alzheimer disease mutations on amyloid beta-protein assembly and toxicity. J Biol Chem, 285:23186-97.

[81] Zhou L, Brouwers N, Benilova I, Vandersteen A, Mercken M, Van Laere K, et al. (2011). Amyloid precursor protein mutation $\mathrm{E} 682 \mathrm{~K}$ at the alternative beta-secretase cleavage beta'-site increases Abeta generation. EMBO Mol Med, 3:291-302.

[82] Kaden D, Harmeier A, Weise C, Munter LM, Althoff $\mathrm{V}$, Rost BR, et al. (2012). Novel APP/A $\beta$ mutation $\mathrm{K} 16 \mathrm{~N}$ produces highly toxic heteromeric $\mathrm{A} \beta$ oligomers. EMBO Mol Med, 4:647-59.

[83] Hendriks L, van Duijn CM, Cras P, Cruts M, Van Hul W, van Harskamp F, et al. (1992). Presenile dementia and cerebral haemorrhage linked to a mutation at codon 692 of the beta-amyloid precursor protein gene. Nat Genet, 1:218-21.

[84] Cras P, van Harskamp F, Hendriks L, Ceuterick C, van Duijn CM, Stefanko SZ, et al. (1998). Presenile Alzheimer dementia characterized by amyloid angiopathy and large amyloid core type senile plaques in the APP 692Ala--> Gly mutation. Acta Neuropathol, 96:253-60.

[85] Kumar-Singh S, Cras P, Wang R, Kros JM, van Swieten J, Lübke U,et al. (2002). Dense-core senile plaques in the Flemish variant of Alzheimer's disease are vasocentric. Am J Pathol, 161:507-20.

[86] Murakami K, Irie K, Morimoto A, Ohigashi H, Shindo M, Nagao M, et al. (2002). Synthesis, aggregation, neurotoxicity, and secondary structure of various A beta 1-42 mutants of familial Alzheimer's disease at positions 21-23. Biochem Biophys Res Commun, 294:5-10.

[87] Wang Z, Natté R, Berliner JA, van Duinen SG, Vinters HV et al. (2000). Toxicity of Dutch (E22Q) and Flemish (A21G) mutant amyloid beta proteins to human cerebral microvessel and aortic smooth muscle cells. Stroke, 31:534-8.

[88] Brooks WS, Kwok JB, Halliday GM, Godbolt AK, Rossor MN, Creasey H, et al. (2004). Hemorrhage is uncommon in new Alzheimer family with Flemish amyloid precursor protein mutation. Neurology, 63:1613-7.

[89] De Jonghe C, Zehr C, Yager D, Prada CM, Younkin S, Hendriks L, et al. (1998). Flemish and Dutch mutations in amyloid beta precursor protein have different effects on amyloid beta secretion. Neurobiol Dis, 5:281-6.
[90]

Tian Y, Bassit B, Chau D, Li YM (2010). An APP inhibitory domain containing the Flemish mutation residue modulates gamma-secretase activity for Abeta production. Nat Struct Mol Biol, 17:151-8.

[91] Tsubuki S, Takaki Y, Saido TC (2003). Dutch, Flemish, Italian, and Arctic mutations of APP and resistance of A to physiologically relevant proteolytic degradation. Lancet, 361:1957-1958.

[92] Morelli L, Llovera R, Gonzalez SA, Affranchino JL, Prelli F, Frangione B, et al. (2003). Differential degradation of amyloid beta genetic variants associated with hereditary dementia or stroke by insulin-degrading enzyme. J Biol Chem, 278:23221-6.

[93] Tomiyama $T$, Nagata $T$, Shimada $H$, Teraoka R, Fukushima A, Kanemitsu H, et al. (2008). A new amyloid beta variant favoring oligomerization in Alzheimer's-type dementia. Ann Neurol, 63:377-87.

[94] Kutoku Y, Ohsawa Y, Kuwano R, Ikeuchi T, Inoue H, Ataka S, et al. (2015). A second pedigree with amyloid-less familial Alzheimer's disease harboring an identical mutation in the amyloid precursor protein gene (E693delta). Intern Med, 54:205-8.

[95] Nishitsuji K, Tomiyama T, Ishibashi K, Ito K, Teraoka R, Lambert MP, et al. (2009). The E693Delta mutation in amyloid precursor protein increases intracellular accumulation of amyloid beta oligomers and causes endoplasmic reticulum stress-induced apoptosis in cultured cells. Am J Pathol, 174:957-69.

[96] Tomiyama T, Matsuyama S, Iso H, Umeda T, Takuma H, Ohnishi K, et al. (2010). A mouse model of amyloid beta oligomers: their contribution to synaptic alteration, abnormal tau phosphorylation, glial activation, and neuronal loss in vivo. $\mathrm{J}$ Neurosci, 30:4845-56.

[97] Umeda T, Tomiyama T, Sakama N, Tanaka S, Lambert MP, Klein WL, et al. (2011). Intraneuronal amyloid $\beta$ oligomers cause cell death via endoplasmic reticulum stress, endosomal/lysosomal leakage, and mitochondrial dysfunction in vivo. J Neurosci Res, 89:1031-42.

[98] Umeda T, Kimura T, Yoshida K, Takao K, Fujita Y, Matsuyama S, et al. (2017). Mutation-induced loss of APP function causes GABAergic depletion in recessive familial Alzheimer's disease: analysis of Osaka mutation-knockin mice. Acta Neuropathol Commun, 5:59.

[99] Kamino K, Orr HT, Payami H, Wijsman EM, Alonso ME, et al. (1992). Linkage and mutational analysis of familial Alzheimer disease kindreds for the APP gene region. Am J Hum Genet, 51:998-1014.

[100] Kalimo H, Lalowski M, Bogdanovic N, Philipson O, Bird TD, Nochlin D, et al. (2013). The Arctic APP mutation leads to Alzheimer's disease pathology with highly variable topographic deposition of differentially truncated A $\beta$. Acta Neuropathol Commun, 1:60.

[101] Basun H, Bogdanovic N, Ingelsson M, Almkvist O, Naslund J, Axelman K, et al. (2008). Clinical and neuropathological features of the arctic APP gene 
mutation causing early-onset Alzheimer disease. Arch Neurol, 65:499-505.

[102] Moro ML, Giaccone G, Lombardi R, Indaco A, Uggetti A, Morbin M, et al. (2012). APP mutations in the Abeta coding region are associated with abundant cerebral deposition of Abeta38. Acta Neuropathol, 124:809-21.

[103] Nilsberth C, Westlind-Danielsson A, Eckman CB, Condron MM, Axelman K, Forsell C, et al. (2001). The 'Arctic' APP mutation (E693G) causes Alzheimer's disease by enhanced Abeta protofibril formation. Nat Neurosci, 4:887-93.

[104] Yamamoto N, Hasegawa K, Matsuzaki K, Naiki H, Yanagisawa K (2004). Environment- and mutationdependent aggregation behavior of Alzheimer amyloid beta-protein. J Neurochem, 90:62-9.

[105] Rönnbäck A, Zhu S, Dillner K, Aoki M, Lilius L, Näslund $J$, et al. Progressive neuropathology and cognitive decline in a single Arctic APP transgenic mouse model. Neurobiol Aging, 32:280-92.

[106] Rönnbäck A, Sagelius H, Bergstedt KD, Näslund J, Westermark GT, Winblad B, et al. (2012). Amyloid neuropathology in the single Arctic APP transgenic model affects interconnected brain regions. Neurobiol Aging, 33:831.e11-9.

[107] Bugiani O, Giaccone G, Rossi G, Mangieri M, Capobianco R, Morbin M, et al. (2010). Hereditary cerebral hemorrhage with amyloidosis associated with the E693K mutation of APP. Arch Neurol, 67:987-95.

[108] Levy E, Carman MD, Fernandez-Madrid IJ, Power MD, Lieberburg I, van Duinen SG, et al. (1990). Mutation of the Alzheimer's disease amyloid gene in hereditary cerebral hemorrhage, Dutch type. Science, 248:1124-6.

[109] Van Broeckhoven C, Haan J, Bakker E, Hardy JA, Van Hul W, Wehnert A, et al. (1990). Amyloid beta protein precursor gene and hereditary cerebral hemorrhage with amyloidosis (Dutch). Science, 248:1120-2.

[110] Fernandez-Madrid I, Levy E, Marder K, Frangione B (1991). Codon 618 variant of Alzheimer amyloid gene associated with inherited cerebral hemorrhage. Ann Neurol, 30:730-3.

[111] Rozemuller AJ, Roos RA, Bots GT, Kamphorst W, Eikelenboom P, Van Nostrand WE (1993). Distribution of beta/A4 protein and amyloid precursor protein in hereditary cerebral hemorrhage with amyloidosis-Dutch type and Alzheimer's disease. Am J Pathol, 142:1449-57.

[112] Timmers WF, Tagliavini F, Haan J, Frangione B (1990). Parenchymal preamyloid and amyloid deposits in the brains of patients with hereditary cerebral hemorrhage with amyloidosis--Dutch type. Neurosci Lett, 118:223-6.

[113] Natté R, Maat-Schieman ML, Haan J, Bornebroek M, Roos RA, van Duinen SG (2001). Dementia in hereditary cerebral hemorrhage with amyloidosisDutch type is associated with cerebral amyloid angiopathy but is independent of plaques and neurofibrillary tangles. Ann Neurol, 50:765-72.
[114] Panegyres PK, Kwok JB, Schofield PR, Blumbergs PC (2005). A Western Australian kindred with Dutch cerebral amyloid angiopathy. J Neurol Sci, 239:75-80.

[115] Herzig MC, Winkler DT, Burgermeister P, Pfeifer M, Kohler E, Schmidt SD, et al. Abeta is targeted to the vasculature in a mouse model of hereditary cerebral hemorrhage with amyloidosis. Nat Neurosci, 7:95460.

[116] Gandy S, Simon AJ, Steele JW, Lublin AL, Lah JJ, Walker LC, et al. (2010). Days to criterion as an indicator of toxicity associated with human Alzheimer amyloid-beta oligomers. Ann Neurol, 68:220-30.

[117] Kaur G, Pawlik M, Gandy SE, Ehrlich ME, Smiley JF, Levy E (2017). Lysosomal dysfunction in the brain of a mouse model with intraneuronal accumulation of carboxyl terminal fragments of the amyloid precursor protein. Mol Psychiatry, 22:981-989.

[118] Shin Y, Cho HS, Rebeck GW, Greenberg SM (2002). Vascular changes in Iowa-type hereditary cerebral amyloid angiopathy. Ann N Y Acad Sci, 977:245-51.

[119] Grabowski TJ, Cho HS, Vonsattel JP, Rebeck GW, Greenberg SM (2001). Novel amyloid precursor protein mutation in an Iowa family with dementia and severe cerebral amyloid angiopathy. Ann Neurol, 49:697-705.

[120] Greenberg SM, Shin Y, Grabowski TJ, Cooper GE, Rebeck GW, Iglesias S, et al. (2003). Hemorrhagic stroke associated with the Iowa amyloid precursor protein mutation. Neurology, 60:1020-2.

[121] Mok T, Chalissery AJ, Byrne S, Costelloe L, Galvin L, Vinters HV, et al. (2014). Familial cerebral amyloid angiopathy due to the iowa mutation in an irish family. Can J Neurol Sci, 41:512-7.

[122] Iwanowski P, Kozubski W, Losy J (2015). Iowa-type hereditary cerebral amyloid angiopathy in a Polish family. J Neurol Sci, 356:202-4.

[123] Van Nostrand WE, Melchor JP, Cho HS, Greenberg SM, Rebeck GW (2001). Pathogenic effects of D23N Iowa mutant amyloid beta -protein. J Biol Chem, 276:32860-6.

[124] Edwards-Lee T, Ringman JM, Chung J, Werner J, Morgan A, St George Hyslop P, et al. (2005). An African American family with early-onset Alzheimer disease and an APP (T714I) mutation. Neurology, 64:377-9.

[125] Kumar-Singh S, De Jonghe C, Cruts M, Kleinert R, Wang R, Mercken M, et al. (2000). Nonfibrillar diffuse amyloid deposition due to a gamma (42)secretase site mutation points to an essential role for N-truncated A beta (42) in Alzheimer's disease. Hum Mol Genet, 9:2589-98.

[126] Szaruga M, Munteanu B, Lismont S, Veugelen S, Horré K, Mercken M, et al. (2017). Alzheimer'sCausing Mutations Shift A $\beta$ Length by Destabilizing $\gamma$-Secretase-A $\beta$ Interactions. Cell, 170:443-456.e14.

[127] De Jonghe C, Esselens C, Kumar-Singh S, Craessaerts K, Serneels S, Checler F, et al. (2001). Pathogenic APP mutations near the gamma-secretase cleavage site differentially affect Abeta secretion and APP C- 
terminal fragment stability. Hum Mol Genet, 10:166571.

[128] Van Broeck B, Vanhoutte G, Pirici D, Van Dam D, Wils H, Cuijt I, et al. (2008). Intraneuronal amyloid beta and reduced brain volume in a novel APP T714I mouse model for Alzheimer's disease. Neurobiol Aging, 29:241-52.

[129] Cruts M, Dermaut B, Rademakers R, Van den Broeck M, Stögbauer F, Van Broeckhoven C et al. (2003). Novel APP mutation V715A associated with presenile Alzheimer's disease in a German family. J Neurol, 250:1374-5.

[130] Zekanowski C, Styczyńska M, Pepłońska B, Gabryelewicz T, Religa D, Ilkowski J, et al. (2003). Mutations in presenilin 1, presenilin 2 and amyloid precursor protein genes in patients with early-onset Alzheimer's disease in Poland. Exp Neurol, 184:9916.

[131] Chen W, Gamache E, Rosenman DJ, Xie J, Lopez MM, Li YM, et al. (2014). Familial Alzheimer's mutations within APPTM increase A $\beta 42$ production by enhancing accessibility of $\varepsilon$-cleavage site. Nat Commun, 5:3037.

[132] Park H-K, Na DL, Lee J-H, Kim J-W, Ki C-S (2008). Identification of PSEN1 and APP gene mutations in Korean patients with early-onset Alzheimer's disease. J Korean Med Sci, 23:213-7.

[133] Guerreiro RJ, Baquero M, Blesa R, Boada M, Brás JM, Bullido MJ, et al. (2010). Genetic screening of Alzheimer's disease genes in Iberian and African samples yields novel mutations in presenilins and APP. Neurobiol Aging, 31:725-31.

[134] Guardia-Laguarta C, Pera M, Clarimón J, Molinuevo JL, Sánchez-Valle R, Lladó A, et al. (2010). Clinical, neuropathologic, and biochemical profile of the amyloid precursor protein $\mathrm{I716 \textrm {F }}$ mutation. J Neuropathol Exp Neurol, 69:53-9.

[135] Sieczkowski E, Milenkovic I, Venkataramani V, Giera R, Ströbel T, Höftberger R, et al. (2015). I716F A $\beta$ PP mutation associates with the deposition of oligomeric pyroglutamate amyloid- $\beta$ and $\alpha$-synucleinopathy with Lewy bodies. J Alzheimers Dis, 44:103-14.

[136] Suárez-Calvet M, Belbin O, Pera M, Badiola N, Magrané J, Guardia-Laguarta C, et al. (2014). Autosomal-dominant Alzheimer's disease mutations at the same codon of amyloid precursor protein differentially alter $A \beta$ production. J Neurochem, 128:330-9.

[137] Terreni L, Fogliarino S, Franceschi M, Forloni G (2002). Novel pathogenic mutation in an Italian patient with familial Alzheimer's disease detected in APP gene. Neurobiol Aging, 23:319.

[138] Eckman CB, Mehta ND, Crook R, Perez-tur J, Prihar G, Pfeiffer E, et al. (1997). A new pathogenic mutation in the APP gene (I716V) increases the relative proportion of A beta 42(43). Hum Mol Genet, 6:20879.

[139] Farlow M, Murrell J, Ghetti B, Unverzagt F, Zeldenrust S, Benson M (1994). Clinical characteristics in a kindred with early-onset
Alzheimer's disease and their linkage to a G-->T change at position 2149 of the amyloid precursor protein gene. Neurology, 44:105-11.

[140] Finckh U, Kuschel C, Anagnostouli M, Patsouris E, Pantes GV, Gatzonis S, et al. (2005). Novel mutations and repeated findings of mutations in familial Alzheimer disease. Neurogenetics, 6:85-9.

[141] Murrell J, Farlow M, Ghetti B, Benson MD (1991). A mutation in the amyloid precursor protein associated with hereditary Alzheimer's disease. Science, 254:979.

[142] Ghetti B, Murrell J, Benson MD, Farlow MR (1992). Spectrum of amyloid beta-protein immunoreactivity in hereditary Alzheimer disease with a guanine to thymine missense change at position 1924 of the APP gene. Brain Res, 571:133-9.

[143] Younkin SG (1994). The amyloid beta protein precursor mutations linked to familial Alzheimer's disease alter processing in a way that fosters amyloid deposition. Tohoku J Exp Med, 174:217-23.

[144] Maruyama K, Tomita T, Shinozaki K, Kume H, Asada H, Saido TC, et al. (1996). Familial Alzheimer's disease-linked mutations at Val717 of amyloid precursor protein are specific for the increased secretion of A beta 42(43). Biochem Biophys Res Commun, 227:730-5

[145] Tamaoka A, Odaka A, Ishibashi Y, Usami M, Sahara N, Suzuki N, et al. (1994). APP717 missense mutation affects the ratio of amyloid beta protein species (A beta 1-42/43 and a beta 1-40) in familial Alzheimer's disease brain. J Biol Chem, 269:32721-4.

[146] Suzuki N, Cheung TT, Cai XD, Odaka A, Otvos L, Eckman C, et al. (1994). An increased percentage of long amyloid beta protein secreted by familial amyloid beta protein precursor (beta APP717) mutants. Science, 264:1336-40.

[147] Games D, Adams D, Alessandrini R, Barbour R, Berthelette P, Blackwell C, et al. (1995). Alzheimertype neuropathology in transgenic mice overexpressing V717F beta-amyloid precursor protein. Nature, 373:523-7.

[148] Masliah E, Rockenstein E, Veinbergs I, Sagara Y, Mallory M, Hashimoto M, et al. (2001). beta-amyloid peptides enhance alpha-synuclein accumulation and neuronal deficits in a transgenic mouse model linking Alzheimer's disease and Parkinson's disease. Proc Natl Acad Sci U S A, 98:12245-50.

[149] Dodart JC, Meziane H, Mathis C, Bales KR, Paul SM, Ungerer A (1999). Behavioral disturbances in transgenic mice overexpressing the $\mathrm{V} 717 \mathrm{~F}$ betaamyloid precursor protein. Behav Neurosci, 113:98290.

[150] Knight WD, Ahsan RL, Jackson J, Cipolotti L, Warrington EK, Fox NC, et al. (2009). Pure progressive amnesia and the APPV717G mutation. Alzheimer Dis Assoc Disord, 23:410-4.

[151] Chartier-Harlin MC, Crawford F, Houlden H, Warren A, Hughes D, Fidani L, et al. (1991). Early-onset Alzheimer's disease caused by mutations at codon 717 
of the beta-amyloid precursor protein gene. Nature, 353:844-6.

[152] Hanger DP, Mann DM, Neary D, Anderton BH (1992). Tau pathology in a case of familial Alzheimer's disease with a valine to glycine mutation at position 717 in the amyloid precursor protein. Neurosci Lett, 145:178-80.

[153] Mann DM, Jones D, Snowden JS, Neary D, Hardy J (1992). Pathological changes in the brain of a patient with familial Alzheimer's disease having a missense mutation at codon 717 in the amyloid precursor protein gene. Neurosci Lett, 137:225-8.

[154] Fidani L, Rooke K, Chartier-Harlin MC, Hughes D, Tanzi R, Mullan M, et al. (1992). Screening for mutations in the open reading frame and promoter of the beta-amyloid precursor protein gene in familial Alzheimer's disease: identification of a further family with APP717 Val-->Ile. Hum Mol Genet, 1:165-8.

[155] Matsumura Y, Kitamura E, Miyoshi K, Yamamoto Y, Furuyama J, Sugihara T (1996). Japanese siblings with missense mutation (717Val --> Ile) in amyloid precursor protein of early-onset Alzheimer's disease. Neurology, 46:1721-3.]

[156] Brooks WS, Martins RN, De Voecht J, Nicholson GA, Schofield PR, Kwok JB, et al. (1995). A mutation in codon 717 of the amyloid precursor protein gene in an Australian family with Alzheimer's disease. Neurosci Lett, 199:183-6.

[157] Sorbi S, Nacmias B, Forleo P, Piacentini S, Latorraca S, Amaducci L (1995). Epistatic effect of APP717 mutation and apolipoprotein $\mathrm{E}$ genotype in familial Alzheimer's disease. Ann Neurol, 38:124-7.

[158] Finckh U, Müller-Thomsen T, Mann U, Eggers C, Marksteiner J, Meins W, et al. (2000). High prevalence of pathogenic mutations in patients with early-onset dementia detected by sequence analyses of four different genes. Am J Hum Genet, 66:110-7.

[159] Talarico G, Piscopo P, Gasparini M, Salati E, Pignatelli M, Pietracupa S, et al. (2010). The London APP mutation (Val717Ile) associated with early shifting abilities and behavioral changes in two Italian families with early-onset Alzheimer's disease. Dement Geriatr Cogn Disord, 29:484-90.

[160] Hardy J, Mullan M, Chartier-Harlin MC, Brown J, Goate A, Rossor M, et al. (1991). Molecular classification of Alzheimer's disease. Lancet, 337:1342-3.

[161] Barber IS, García-Cárdenas JM, Sakdapanichkul C, Deacon C, Zapata Erazo G, Guerreiro R, et al. (2016). Screening exons 16 and 17 of the amyloid precursor protein gene in sporadic early-onset Alzheimer's disease. Neurobiol Aging, 39:220.e1-7.

[162] Lantos PL, Luthert PJ, Hanger D, Anderton BH, Mullan M, Rossor M (1992). Familial Alzheimer's disease with the amyloid precursor protein position 717 mutation and sporadic Alzheimer's disease have the same cytoskeletal pathology. Neurosci Lett, 137:221-4.

[163] Theuns J, Marjaux E, Vandenbulcke M, Van Laere K, Kumar-Singh S, Bormans G, et al. (2006). Alzheimer dementia caused by a novel mutation located in the APP C-terminal intracytosolic fragment. Hum Mutat, 27:888-96.

[164] Muratore CR, Rice HC, Srikanth P, Callahan DG, Shin T, Benjamin LN, et al. (2014). The familial Alzheimer's disease APPV717I mutation alters APP processing and Tau expression in iPSC-derived neurons. Hum Mol Genet, 23:3523-36.

[165] Moechars D, Dewachter I, Lorent K, Reversé D, Baekelandt V, Naidu A, et al. (1999). Early phenotypic changes in transgenic mice that overexpress different mutants of amyloid precursor protein in brain. J Biol Chem, 274:6483-92.

[166] Van Dorpe J, Smeijers L, Dewachter I, Nuyens D, Spittaels K, Van den Haute C, et al. (2000). Prominent cerebral amyloid angiopathy in transgenic mice overexpressing the london mutant of human APP in neurons. Am J Pathol, 157:1283-98.

[167] Kawasumi M, Chiba T, Yamada M, Miyamae-Kaneko M, Matsuoka M, Nakahara J, et al. (2004). Targeted introduction of V642I mutation in amyloid precursor protein gene causes functional abnormality resembling early stage of Alzheimer's disease in aged mice. Eur J Neurosci, 19:2826-38.

[168] Murrell JR, Hake AM, Quaid KA, Farlow MR, Ghetti B (2000). Early-onset Alzheimer disease caused by a new mutation (V717L) in the amyloid precursor protein gene. Arch Neurol, 57:885-7.

[169] Godbolt AK, Beck JA, Collinge JC, Cipolotti L, Fox NC, Rossor MN (2006). A second family with familial $\mathrm{AD}$ and the V717L APP mutation has a later age at onset. Neurology, 66:611-2.

[170] Abe M, Sonobe N, Fukuhara R, Mori Y, Ochi S, Matsumoto T, et al. (2012). Phenotypical difference of Amyloid Precursor Protein (APP) V717L mutation in Japanese family. BMC Neurol, 12:38.

[171] Ghetti B, Hake AM, Murrell JR, Epperson F, Farlow MR, Vidal R, et al. (2008). Familial Alzheimer disease associated with the V717L amyloid precursor protein gene mutation: Neuropathological characterization. Alzheimers Dement, 4(4 Suppl): T585.

[172] Sassi C, Guerreiro R, Gibbs R, Ding J, Lupton MK, Troakes C, et al. (2014). Exome sequencing identifies 2 novel presenilin 1 mutations (p.L166V and p.S230R) in British early-onset Alzheimer's disease. Neurobiol Aging, 35: 2422.e13-6.

[173] Hooli BV, Mohapatra G, Mattheisen M, Parrado AR, Roehr JT, Shen Y, et al. (2012). Role of common and rare APP DNA sequence variants in Alzheimer disease. Neurology, 78:1250-7.

[174] Kwok JB, Li QX, Hallupp M, Whyte S, Ames D, Beyreuther K, et al. (2000). Novel Leu723Pro amyloid precursor protein mutation increases amyloid beta42(43) peptide levels and induces apoptosis. Ann Neurol, 47:249-53.

[175] Peng XL, Hou L, Xu SH, Hua Y, Zhou SJ, Zhang Y, et al. (2014). Novel APP K724M mutation causes Chinese early-onset familial Alzheimer's disease and increases amyloid- $\beta 42$ to amyloid- $\beta 40$ ratio. Neurobiol Aging, 35:2657.e1-2657.e6. 
[176] Selkoe DJ, Hardy J (2016). The amyloid hypothesis of Alzheimer's disease at 25 years. EMBO Mol Med, 8:595-608.

[177] Kim J, Onstead L, Randle S, Price R, Smithson L, Zwizinski C, et al. (2007). Abeta40 inhibits amyloid deposition in vivo. J Neurosci, 27:627-33.

[178] Moore BD, Martin J, de Mena L, Sanchez J, Cruz PE, Ceballos-Diaz C, et al. (2018). Short A $\beta$ peptides attenuate A $\beta 42$ toxicity in vivo. J Exp Med, 215:283301.

[179] Bateman RJ, Xiong C, Benzinger TL, Fagan AM, Goate A, Fox NC, et al. (2012). Clinical and biomarker changes in dominantly inherited Alzheimer's disease. N Engl J Med, 367:795-804.

[180] Lemere CA, Blustzjan JK, Yamaguchi H, Wisniewski T, Saido TC, Selkoe DJ (1996). Sequence of deposition of heterogeneous amyloid b-peptides and Apo $\mathrm{E}$ in Down syndrome: implications for initial events in amyloid plaque formation. Neurobiol Dis, 3: 16-32.

[181] Wolfe MS (2012). The role of tau in neurodegenerative diseases and its potential as a therapeutic target. Scientifica (Cairo), 2012:796024.

[182] Roberson ED, Scearce-Levie K, Palop JJ, Yan F, Cheng IH, Wu T, et al. (2011). Reducing endogenous tau ameliorates amyloid beta induced deficits in an Alzheimer's disease mouse model. Science, 316:750754.

[183] Arriagada PV, Growdon JH, Hedley-Whyte ET, Hyman BT (1992). Neurofibrillary tangles but not senile plaques parallel duration and severity of Alzheimer's disease. Neurology, 42(3 Pt 1):631-9.

[184] Masliah E, Iimoto DS, Mallory M, Albright T, Hansen L, Saitoh T (1992). Casein kinase II alteration precedes tau accumulation in tangle formation. Am J Pathol, 140:263-8.

[185] Bussière T, Giannakopoulos P, Bouras C, Perl DP, Morrison JH, Hof PR (2003). Progressive degeneration of nonphosphorylated neurofilament protein-enriched pyramidal neurons predicts cognitive impairment in Alzheimer's disease: stereologic analysis of prefrontal cortex area 9. J Comp Neurol, 463:281-302.

[186] Liou YC, Sun A, Ryo A, Zhou XZ, Yu ZX, Huang HK, et al. (2003). Role of the prolyl isomerase Pin1 in protecting against age-dependent neurodegeneration. Nature, 424:556-561.

[187] Farizatto KLG, Ikonne US, Almeida MF, Ferrari MFR, Bahr BA (2017). A $\beta 42-$ mediated proteasome inhibition and associated tau pathology in hippocampus are governed by a lysosomal response involving cathepsin B: Evidence for protective crosstalk between protein clearance pathways. PLoS One, 12: e0182895.

[188] LaFerla FM, Green KN, Oddo S (2007). Intracellular amyloid-beta in Alzheimer's disease. Nat Rev Neurosci, 8:499-509.

[189] Casas C, Sergeant N, Itier JM, Blanchard V, Wirths O, van der Kolk N, et al. (2004). Massive CA1/2 neuronal loss with intraneuronal and $\mathrm{N}$-terminal truncated
Abeta42 accumulation in a novel Alzheimer transgenic model. Am J Pathol, 165:1289-300.

[190] Pera M, Alcolea D, Sánchez-Valle R, GuardiaLaguarta C, Colom-Cadena M, Badiola N, et al. (2013). Distinct patterns of APP processing in the CNS in autosomal-dominant and sporadic Alzheimer disease. Acta Neuropathol, 125:201-13.

[191] Lahiri DK, Kotwal GJ, Farlow MR, Sima A, Kupsky W, Sarkar FH, et al. (2002). The role of the carboxylterminal fragments of amyloid precursor protein in Alzheimer's disease. Ann N Y Acad Sci, 973:334-9.

[192] García-Ayllón MS, Lopez-Font I, Boix CP, Fortea J, Sánchez-Valle R, Lleó A, et al. (2017). C-terminal fragments of the amyloid precursor protein in cerebrospinal fluid as potential biomarkers for Alzheimer disease. Sci Rep, 7:2477.

[193] Kametani F, Haga S (2015). Accumulation of carboxy-terminal fragments of APP increases phosphodiesterase 8B. Neurobiol Aging, 36:634-7.

[194] Kim S, Sato Y, Mohan PS, Peterhoff C, Pensalfini A, Rigoglioso A, et al. (2016). Evidence that the rab5 effector APPL1 mediates APP- $\beta C T F$-induced dysfunction of endosomes in Down syndrome and Alzheimer's disease. Mol Psychiatry, 21:707-16.

[195] Kim HS, Kim EM, Lee JP, Park CH, Kim S, Seo JH, et al. (2003). C-terminal fragments of amyloid precursor protein exert neurotoxicity by inducing glycogen synthase kinase-3beta expression. FASEB J, 17:1951-3.

[196] Lauritzen I, Pardossi-Piquard R, Bauer C, Brigham E, Abraham JD, Ranaldi S, et al. (2012). The $\beta$-secretasederived $\mathrm{C}$-terminal fragment of $\beta$ APP, C99, but not $\mathrm{A} \beta$, is a key contributor to early intraneuronal lesions in triple-transgenic mouse hippocampus. J Neurosci, 32:16243-1655.

[197] Schettini G, Govoni S, Racchi M, Rodriguez G (2010). Phosphorylation of APP-CTF-AICD domains and interaction with adaptor proteins: signal transduction and/or transcriptional role--relevance for Alzheimer pathology. J Neurochem, 115:1299-308.

[198] Gerakis Y, Hetz C (2018). Emerging roles of ER stress in the etiology and pathogenesis of Alzheimer's disease. FEBS J, 285:995-1011.

[199] Suga K, Saito A, Mishima T, Akagawa K (2015). ER and Golgi stresses increase ER-Golgi SNARE Syntaxin5: Implications for organelle stress and $\beta$ APP processing. Neurosci Lett, 604:30-5.

[200] Viana RJ, Fonseca MB, Ramalho RM, Nunes AF, Rodrigues CM (2010). Organelle stress sensors and cell death mechanisms in neurodegenerative diseases. CNS Neurol Disord Drug Targets, 9:679-92.

[201] Joshi G, Chi Y, Huang Z, Wang Y (2014). A $\beta$-induced Golgi fragmentation in Alzheimer's disease enhances A $\beta$ production. Proc Natl Acad Sci U S A, 111: E1230-9.

[202] Hill S, Van Remmen H (2014). Mitochondrial stress signaling in longevity: a new role for mitochondrial function in aging. Redox Biol, 2:936-44.

[203] Wang C, Telpoukhovskaia MA, Bahr BA, Chen X, Gan L (2008). Endo-lysosomal dysfunction: a 
converging mechanism in neurodegenerative diseases. Curr Opin Neurobiol. 48:52-58.

[204] Bennett DA, Schneider JA, Arvanitakis Z, Kelly JF, Aggarwal NT, Shah RC, et al. (2006). Neuropathology of older persons without cognitive impairment from two community-based studies. Neurology, 66:183744.

[205] Price JL, McKeel DW Jr, Buckles VD, Roe CM, Xiong C, Grundman M, et al. (2009). Neuropathology of nondemented aging: presumptive evidence for preclinical Alzheimer disease. Neurobiol Aging, 30:1026-36.

[206] Edison P, Archer HA, Hinz R, Hammers A, Pavese N, Tai YF, et al. (2007). Amyloid, hypometabolism, and cognition in Alzheimer disease: an [11C] PIB and [18F] FDG PET study. Neurology, 68:501-8.

[207] Li Y, Rinne JO, Mosconi L, Pirraglia E, Rusinek H, DeSanti S, et al. (2008). Regional analysis of FDG and PIB-PET images in normal aging, mild cognitive impairment, and Alzheimer's disease. Eur J Nucl Med Mol Imaging, 35:2169-81.

[208] Robakis NK (2011). Mechanisms of AD neurodegeneration may be independent of $A \beta$ and its derivatives. Neurobiol Aging, 32:372-9.

[209] Shen J, Kelleher RJ (2007). The presenilin hypothesis of Alzheimer's disease: evidence for a loss-of-function pathogenic mechanism. Proc Natl Acad Sci U S A, 104:403-9.

[210] Li B, Gonzalez-Toledo ME, Piao CS, Gu A, Kelley RE, Zhao LR (2011). Stem cell factor and granulocyte colony-stimulating factor reduce $\beta$-amyloid deposits in the brains of APP/PS1 transgenic mice. Alzheimers Res Ther, 3:8.

[211] Miller VM, Gouvion CM, Davidson BL, Paulson HL (2004). Targeting Alzheimer's disease genes with RNA interference: an efficient strategy for silencing mutant alleles. Nucleic Acids Res, 32:661-8.

[212] Alvarez-Miranda EA, Sinnl M, Farhan H (2015). Alteration of Golgi Structure by Stress: A Link to Neurodegeneration? Front Neurosci, 9:435. 